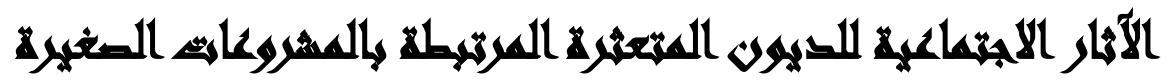 \\ وهنئهية المغر
}

\section{[0]}

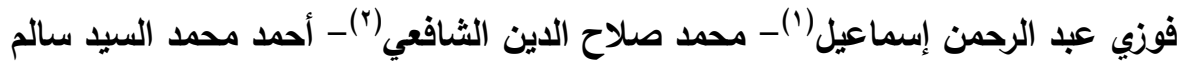

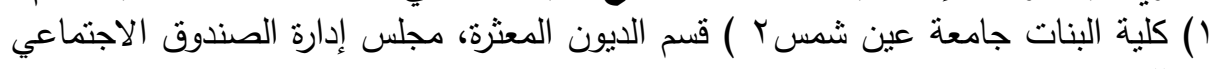
للتنمية

\section{المستخليف}

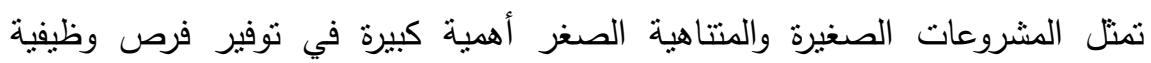

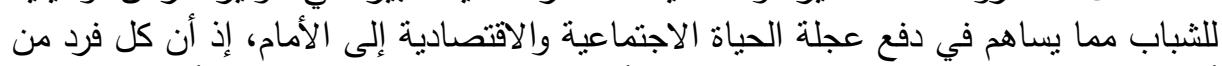

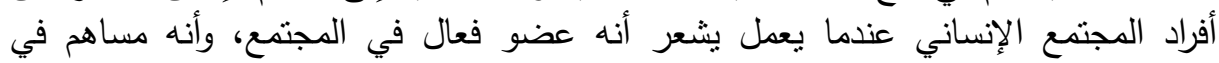

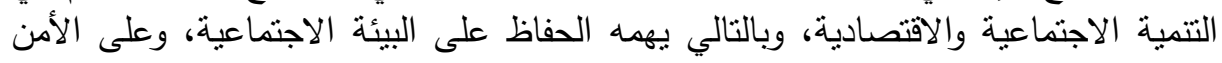

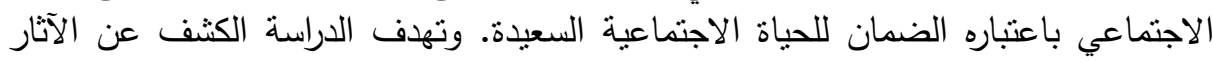

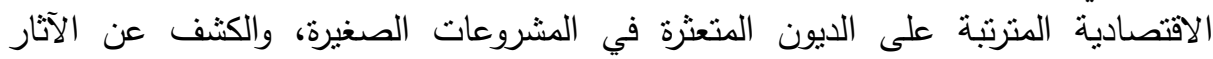

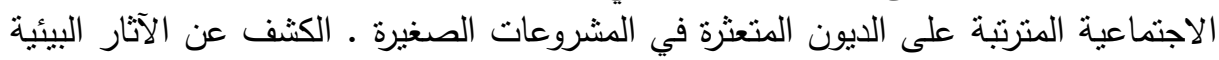

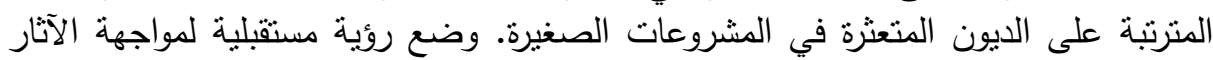

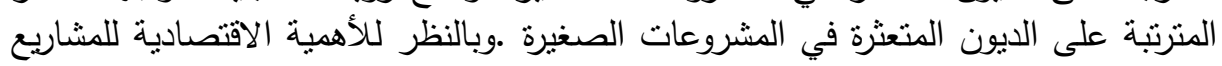

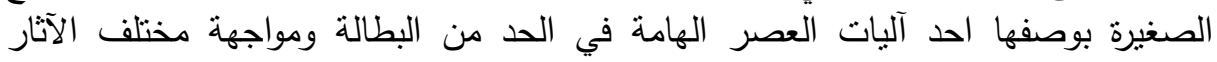

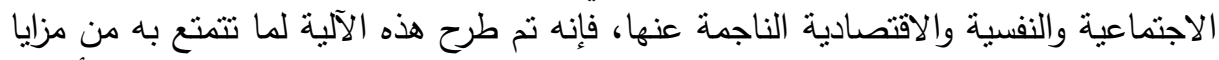

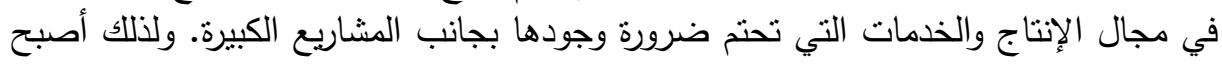

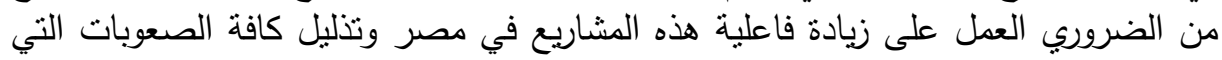

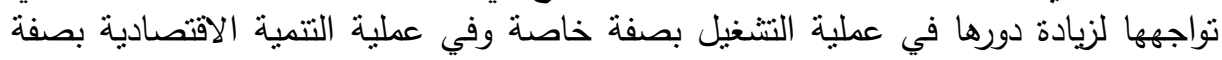

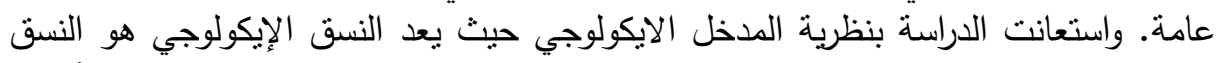

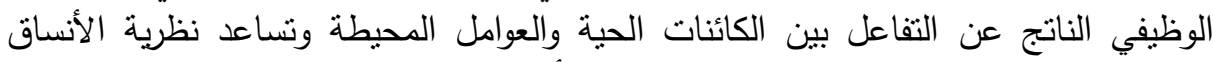

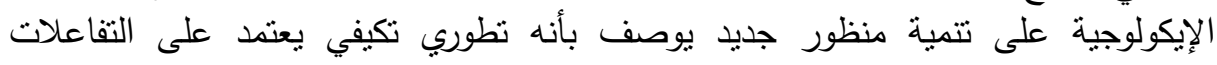

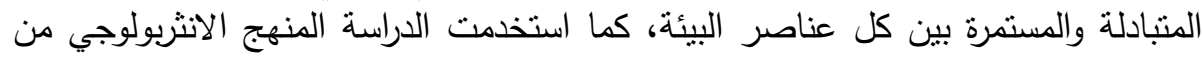

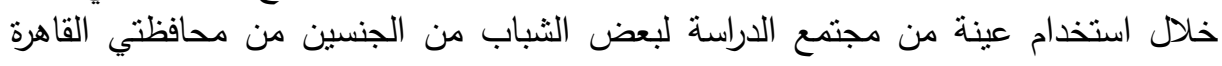

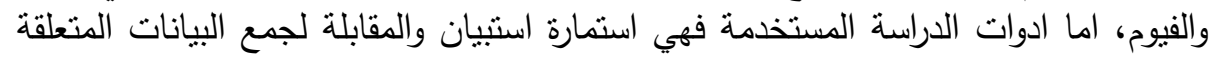

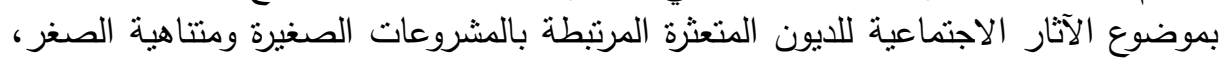

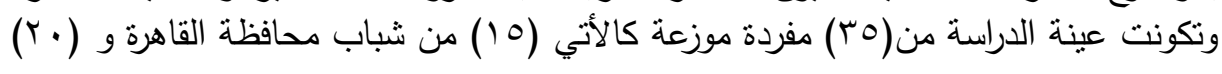

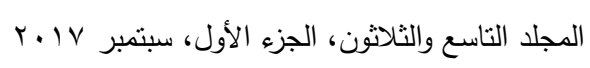




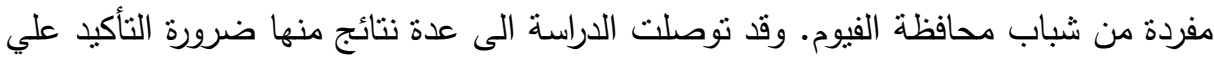

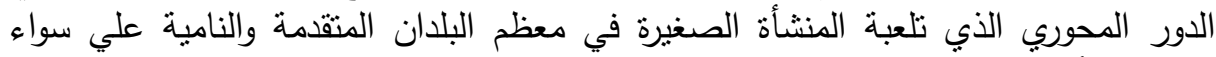

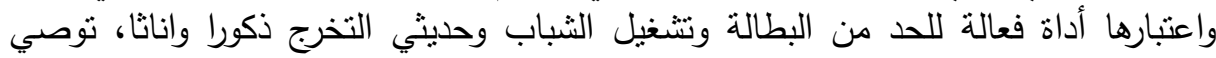
الدراسة بتحقيق اهمية زيادة التتسيق بين الوزارات الماتية المركزية والادارات المحلية لمواجية

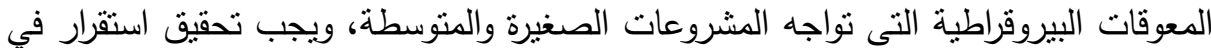

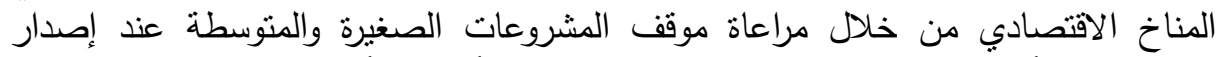

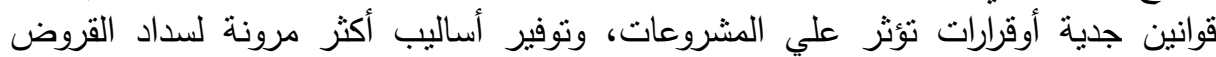
وتخفيض أسعار الفائدة عليها.

\section{Axis}

تبلورت في مصر قناعة بأهمية المشروعات الصغيرة في السنوات الاخيرة لمواجهة الكثير من المشكلات، وفي غضون هذه القناعة تعددت شبكات الأمان الاجتماعي والحماية الاجتماعية، ولعبت دوراً فاعلاً في تمويل المشروعات الصغيرة والاهتمام بها باعنبارها آلية لمواجهة مشكلات الفقر والبطالة وتحول فلسفات مواجهة الفقر تتضمن الاستفادة من طاقة

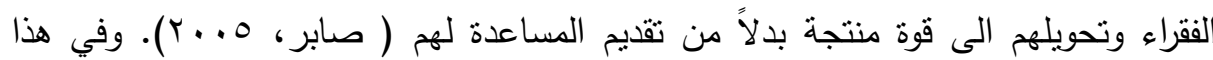
الصدد برز دور الصندوق الاجتماعية للتتمية وبعض الجهات الاخري في تحيل المشروعات الصغيرة لقوي منتجة في المجتمع وحل بعض الشكلات الاقتصادية ومن هذا يرى كثير من الصناعنه الاقتصاديين أن نطوير المشروعات الصغيرة ونتجيع اقامتها من أهم روافد عملية التتمية الاقتصادية والاجتماعية في الدول بشكل عام والدول النامية بشكل خاص وذلك باعنبارها منطلقاً أساسياً لزيادة الطاقة الانتاجية من ناحية والمساهمة في معالجة مشكلتي الفقر والبطالة

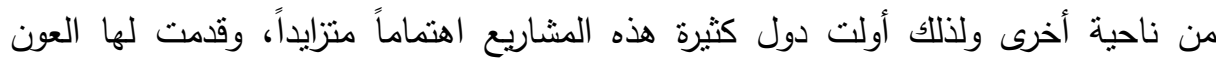

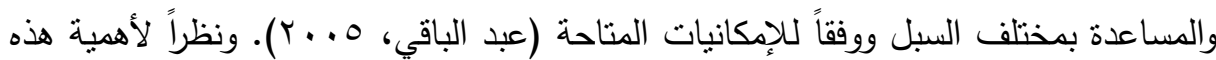
المشروعات أخذت معظم الدول النامية تركز الجهود عليها حيث أصبحت تشجع إقامة الصناعات الصغيرة والمتوسطة وخاصة بعد أن أثتبت قدرتها وكفاءتها في معالجة المشكلات الرئيسية التي نواجه الاقتصاديات المختلفة، وبدرجة أكبر من الصناعات الكبيرة. ويأتي الاهتمام المتزايد على الصعيدين الرسمي والأهلي بالمشروعات الصغيرة والمتوسطة، لأنها 
بالإضافة إلى قدرتها الاستيعابية الكبيرة للأيدي العاملة، يقل حجم الاستثمار فيها كثيراً

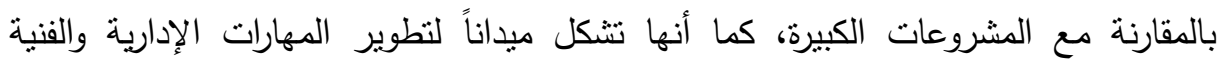
والإنتاجية والتسويقية، وتقتح مجالاً واسعاً أمام المبادرات الفردية والتوظيف الذاتي، مما يخفف

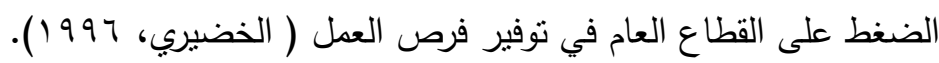

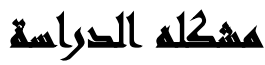

أدت التحولات الاقتصادية والسياسية إلي تغييرات جذرية في عالمنا المعاصر سواء من الناحية الاقتصادية أو السياسية وقد خلقت هذه التغييرات أوضاعاً جديدة تتعلق بأدوار

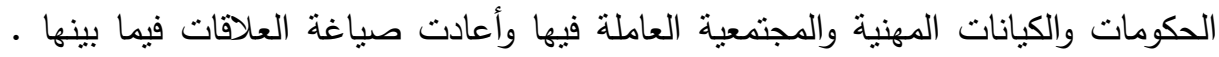
ومع هذه التغيرات العالمية وما ترتب عليها من أثار ونتائج، بات من الواجب محاولة تجاوز الركود والجمود العالمي مع الأمل المتجدد في استعادة جزء من مشهد النبوغ والتفوق الذي مني

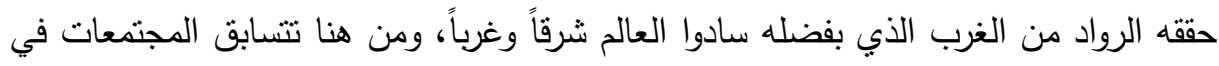
وضع خطط تتموية بهدف النهوض بالبيئة الاقتصادية والاجتماعية للمجتمع (هشام على لئى عبدالخالق: . . . Y) وأدت هذه التغيرات في المجتمع والسعي إلي التتمية إلي ظهور شبكة

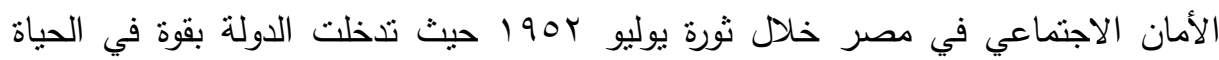

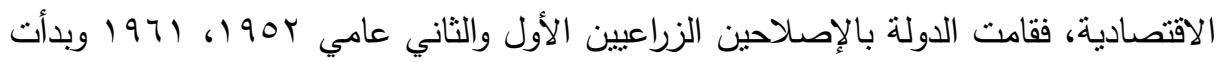
الدولة في تأميم المشروعات الصناعية والتجارية الكبرى، وتوسعت في نظام التأمينات الاجتماعية وقامت بنشر التعليم بجميع مراحله وقامت كذلك بنشر الخدمات الصحية وخاصة

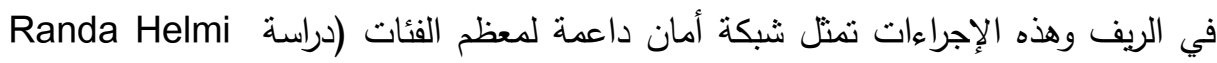
2002 ). ويتوقف نجاح أي مجتمع في مواجهة مشكلاته الاقتصادية علي قدرته علي تعبئة

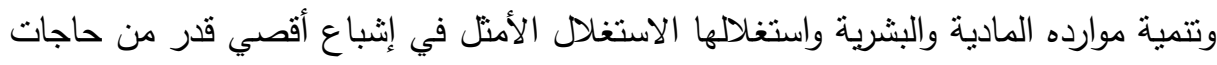

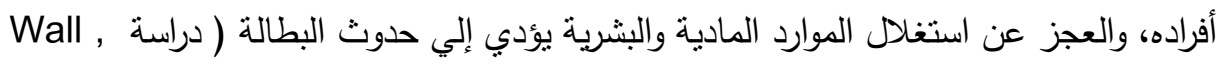
rBruce

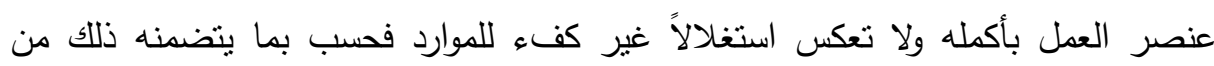
إهدار وتبديد لإنتاج كان يمكن تحقيقه ولكنها تعني ما هو أكثر من ذلك فهي مشكلة اجتماعية

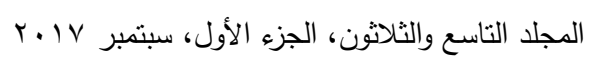


بالدرجة الأولي تمس أفراد المجتمع وتؤثر بشدة علي سلوكياتهم وتصرفاتهم ومن هنا تتبع

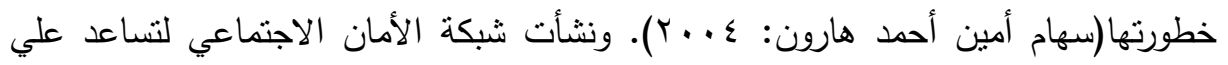

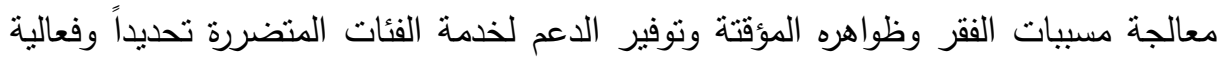

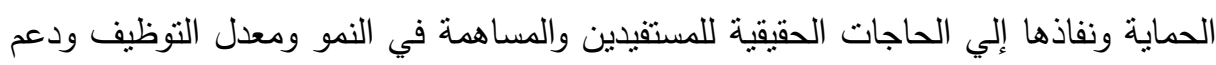

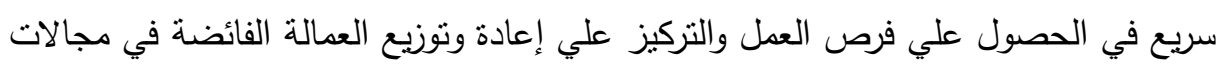
جديدة من النشاط الاقتصادي (ريم محمد حسن سلامة: 10 ـ ب ) ). هذه الدراسة تبحث في مشكلة هامة وهي الاثار الناتجة عن الديون المتعثرة وما اسبابها وكيفية مواجهتها للقروض الممنوحة من الصندوق الاجتماعي للتنمية، كذللك فإن تساؤلات الدراسة هي:

\section{أسريلا المهيه}

كيف نشأت الديون المتعثرة للمشروعات الصغيرة والمتناهية الصغر؟ ويتفرع من هذا

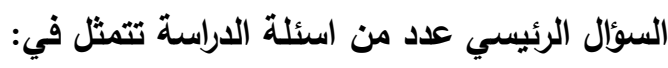
ا-ما الآثار الاقتصادية المترتبة على الديون المتعثرة في المشروعات الصغيرة والمتتاهية

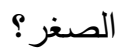
r-ما الآثار الاجتماعية المترتبة على الديون المتعثرة في المشروعات الصغيرة والمتتاهية

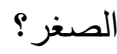
ب-ما الآثار البيئية المترنبة على الديون المتعثرة في المشروعات الصغيرة والمتتاهية الصغر؟ ع-ما أمكانية وضع رؤية مستقبلية لمواجهة الآثار المترتبة على الديون المتعثرة في المشروعات الصغيرة والمتتاهية الصغر؟

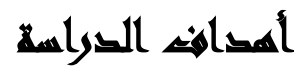

• الكثف عن الآثار الاقتصادية المترتبة على الديون المتعثرة في المشروعات الصغيرة

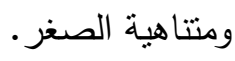


• الكثف عن الآثار الاجتماعية المترتبة على الديون المتعثرة في المشروعات الصغيرة ومتتاهية الصغر

• الكثف عن الآثار البيئية المترتبة على الديون المتعثزة في المشروعات الصغيرة ومتتاهية الصغر. • وضع رؤية مستقلية لمواجهة الآثار المنرتبة على الديون المتعثرة في المشروعات الصغيرة ومتتاهية الصغر .

\section{أهمية الصواسمة}

ا -تعاظم اهتمام المجتمع الدولي والمحلي بالنهوض بالثباب لذلك لا بد من استتمار قدراتهم

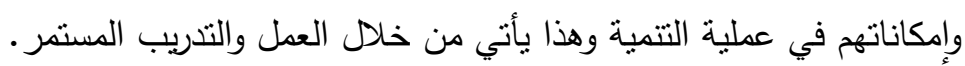

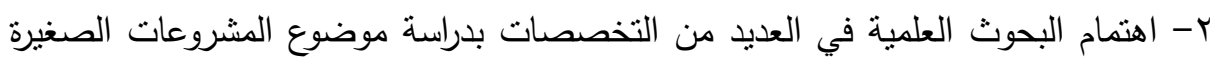

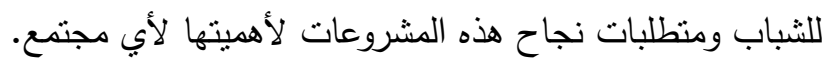

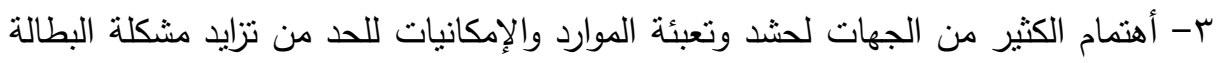

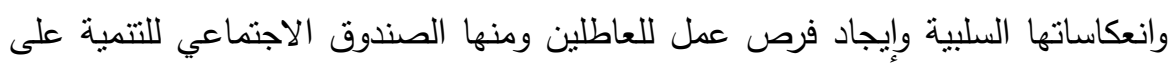
سبيل المثال.

ع -تزداد أهية هذه الدراسة في الوقت الراهن حيث تراجعت معدلات التتمية الاقتصادية في

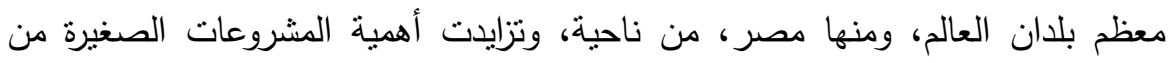
ناحيةٍ أخرى كمخرج وحل كثير من المشكلات الاجتماعية التى تواجة الثباب.

\section{منهمجية القواسمة}

استخدمت الدراسة الحالية منهج الانثربولوجي، كما اعتمدت على المنهج الوصفي، الذي

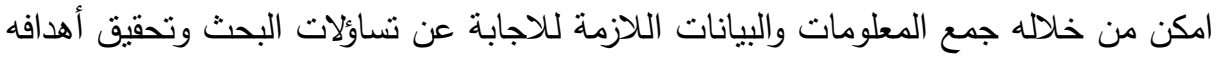
وذللك بالرجوع الى ادبيات التربية والدارسات ذات الصلة بالموضوع وتحليلهاتهات كما ان الدراسة

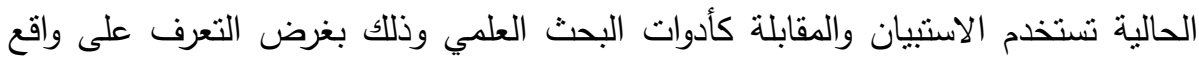
موضع البحث.

$$
\text { المجلد التاسع والثلاثثون، الجزء الأول، سبتمبر r. V }
$$




\section{همخاهيه القراسمة}

1 - مفهوم الاثار الاجتماعية: عرفت بأنها " تغيير الافكار في اللاشعور بصورة مثالية لغاية برمجة الفرد عليها وتفعيلها حراكا عفويا في سلوكه الفردي وسلوكه الاجتماعي

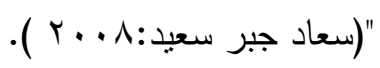
Y - مفهوم الايون المتعثرة: فالتعثر المالي هو مواجهة المنشأة لظروف "طارئة غير منوقعة" تؤدي إلى عدم قدرتها على توليد مردود اقتصادي أو فائض نشاط يكفي لسداد النزاماتها في الأجل القصير (محسن احمد الخضيري : 1997 ( 199 ب- مفهوم المشروع الصغير: المشروعات الصغيرة بأنها " تلك المشروعات التي بديرها مالك واحد ويتكفل بكامل المسؤولية بأبعادها الطويلة الأجل (الإستراتيجية) والقصيرة الأجل باله

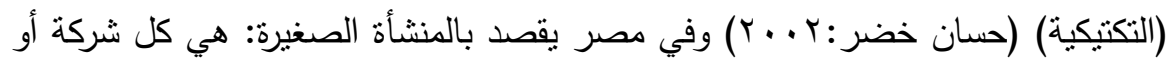

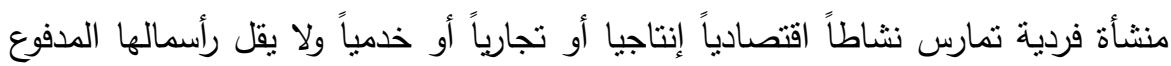
عن خمسين ألف جنيه ولا يتجاوز مليون جنيه ولا يزيد عدد العاملين فيها على خمسين

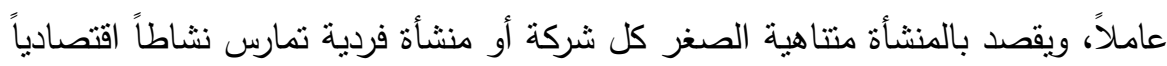

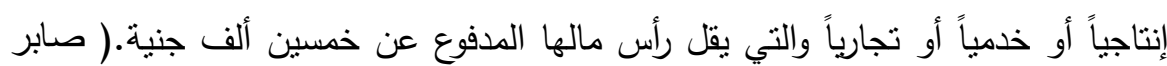

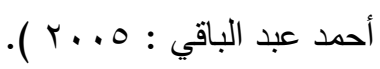

ع - مفهوم المشروع المتناهي الصغر : هي كل نشاط لانتاج سلع وخدمات نسنعنل فية تقنية غير معقدة ويتميز بقلة راس المال المستثمر ويعتمد علي تشغيل العمالة بشكل اكبر (1) وهي تلاك المشروعات التي يعمل بها عمالة قليلة تتراوخ ما بين عامل واحد ولايزيد عن عشرة عمال.

\section{السراسايت الساريه}

أهم الدراسات العربية والأجنبية الحديثة التى تتاولت المشروعات الصغيرة ومتتاهية الصغر والصندوق الاجتماعى للتتمية في محاولة من الباحث للتوصل إلى تعقيب عام والربط لتابله

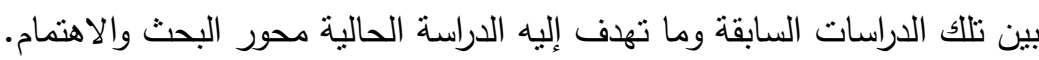




\section{أولاً: الدراسات المرتبطة بالاثار الاجتماعية للايون المتعثرة:}

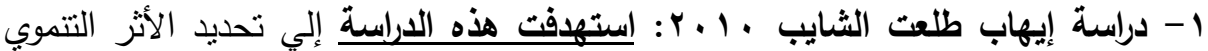

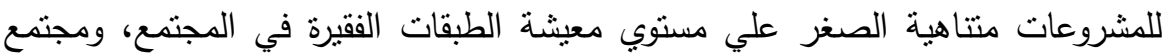
الدراسة ويتمثل فى جميع المستفيدين من تمويل المشروعات المتناهية الصغر فى جمهورية فئية

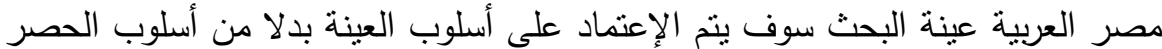

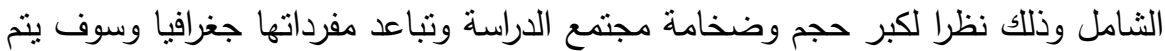

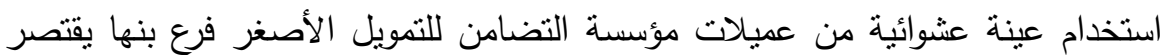

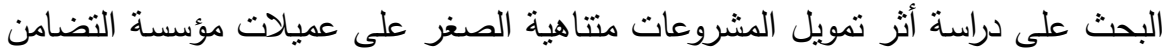

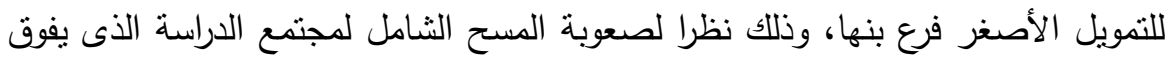

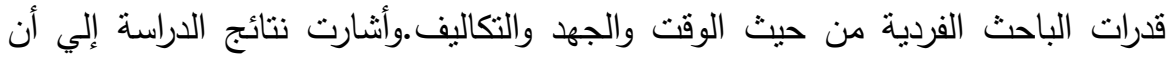

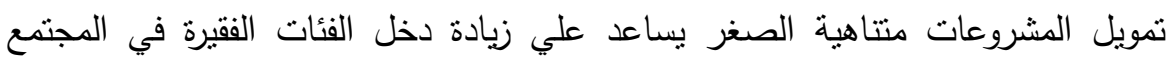

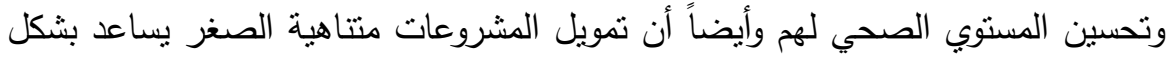

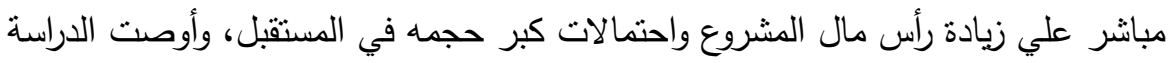

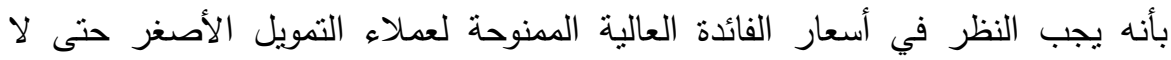
تصبح هذه القروض سبياً في زيادة الإققار بدلاً من كونها مساعده للخروج من دائرة الفقر.

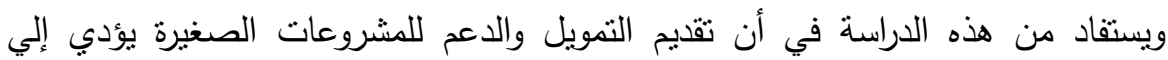

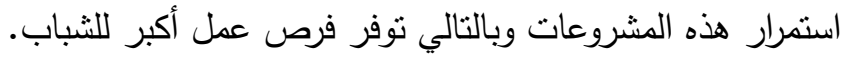

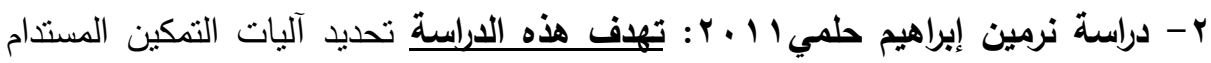

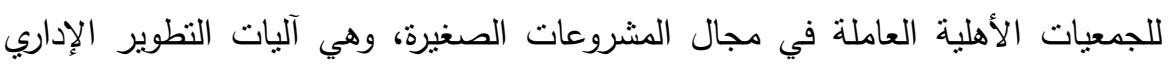

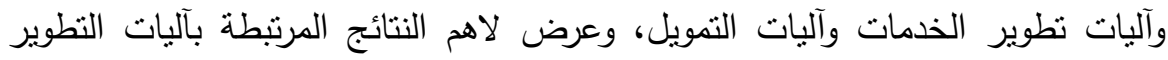

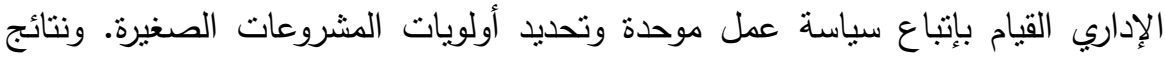

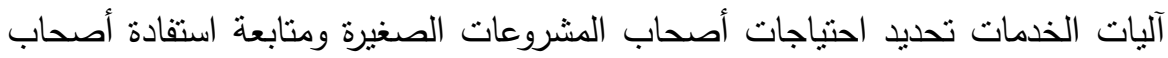
المشروعات الصغيرة من خدمات الجمعية. النتائج المرتبطة بآليات التمويل تطوير الجمعية الئنية

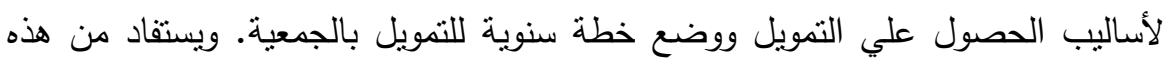

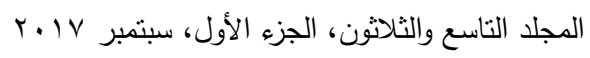


الدراسة في أن تحديد احتياجات الثباب أصحاب المشروعات القائمة ومتابعة استفادتهم من خدمات الجمعية يؤدي إلي استمرار هذه المشروعات.

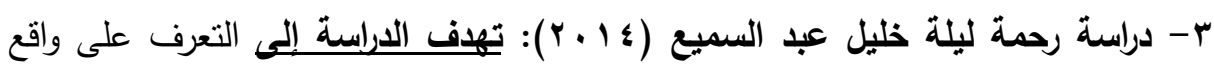

الإدارة الاستراتيجية في الصندوق الاجتماعي للتنمية، والتعرف على تأثنر عوامل البيئة

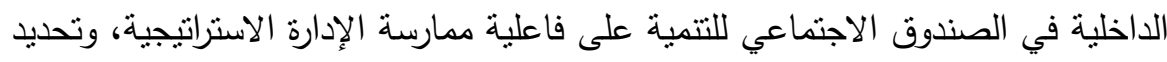

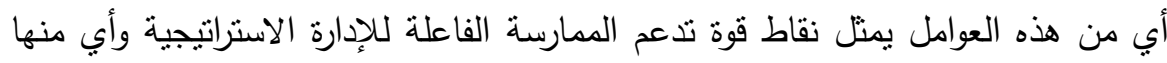

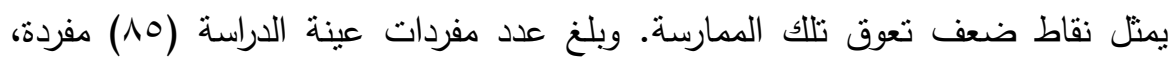
ولتحقيق أهداف الدراسة قامت الباحثة بعمل استمارة استقصاء لجمع البيانات اللازمة لاختبار فروض الدراسة، وتم ثقسيمها إلى ثلاثة أجزاء الأول يقيس ثقافة المنظمة والإدارة

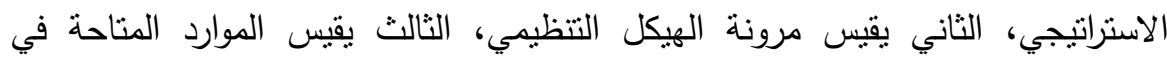

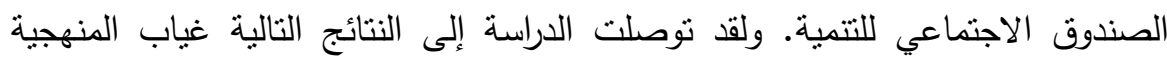

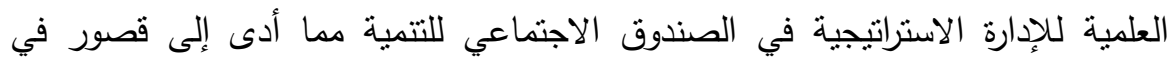
ممارستها، الثقافة التنظيمية في الصندوق الاجتماعي للتنمية تعد نقطة ضعف تعوق ممارسة الإدارة الاستراتيجية بفعالية، افتقار المشاركة بين العاملين على مختلف المستويات في وضع الخطة الاسترانيجية لاتتسجم أهداف الصندوق مع الثقافة التتظيمية السائدة فيه،

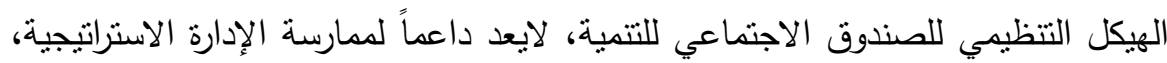

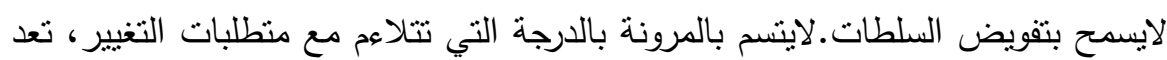
الموارد المالية والمادية والفنية والمعلوماتية من نقاط القوة في الصندوق الاجتماعي للتنمية والتي تدعم الممارسة الفاعلة للإدارة الاستراتيجية ولكن لابد من إعادة النظر بشأن الموارد

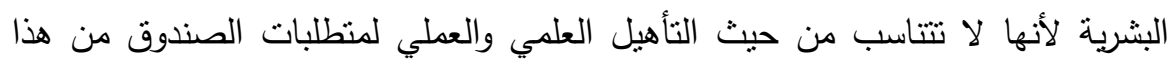

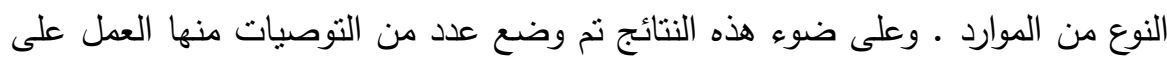

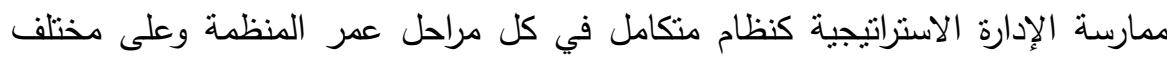
المستويات، مشاركة المستويات الإدارية المختلفة في عمليات الإدارة الاستراتيجية، تعديل 
الثقافة التتظيمية طبقاً لمتطلبات تتفيذ الاستراتيجية، تبني هياكل نتظيمية أكثر مرونة أكثر ملاعمة للمستجدات البيئية الحالية، ربط تخطيط الموارد البشرية باستراتيجية المنظمة.

ثانياً: الاراسات المرتبطة بالمشروعات الصغيرة ومتناهية الصغر.

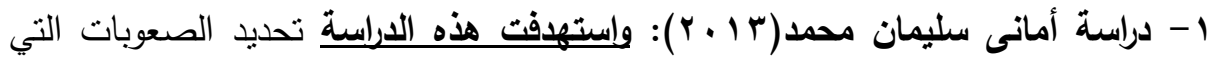
تواجه المستقيدين من المشروعات الصغيرة عند تتفيذ المشروع، وأثارت نتائج الدراسة إلى الى أن الصعوبات التي تواجه المشروعات الصغيرة هي زيادة الفائدة على القروض ومحدودية رأس المال المستثر وقلة انتشار مراكز التدريب المهني لمختلف فئات سكان القرى. وتستفيد الدراسة الحالية من هذه الدراسة في تحديد الصعوبات التي تواجه المستقيدين من هن

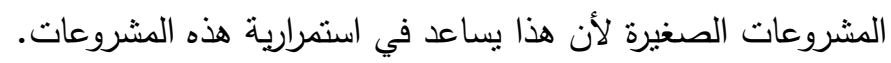

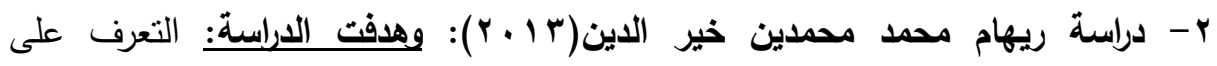

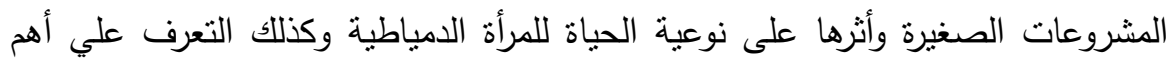

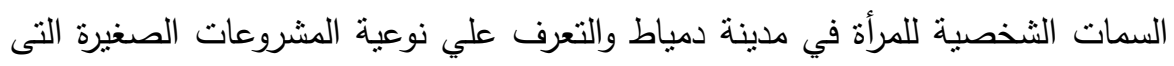

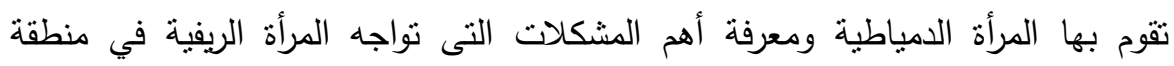
الدراسة وكذلك المعوقات التى تعوق مشاركة المرأة الريفية في المشروعات الصغيرة وتنتكون عينة الدراسة من (10) سيدة من الريفيات والعاملات بالمشروعات الصغيرة بمركز فارسكور بمحافظة دمياط ومن اهم الادوات التي استخدمتها الدراسة الاستبيان والمقابلة

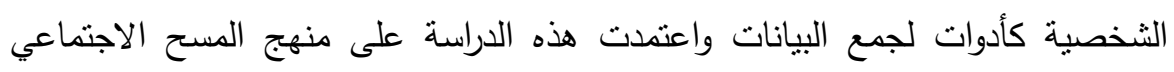

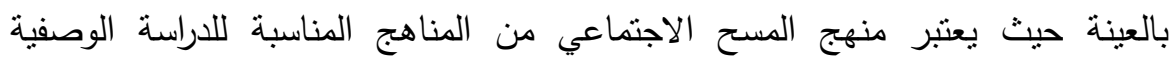

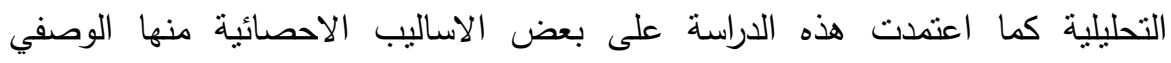

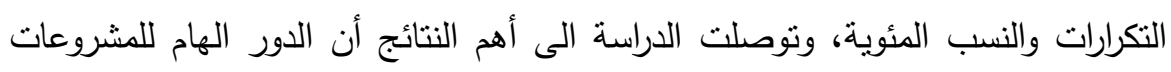
الصغيرة تمنل في توفير فرص العمل ولحد من البطالة وزيادة دخل الاسر المنتجة ورفع

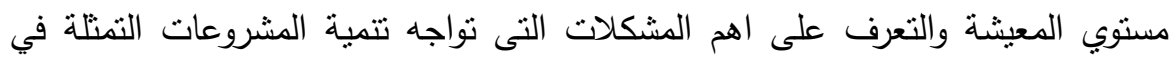

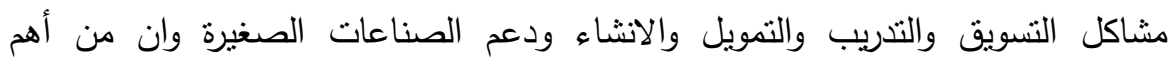
المشكلات التى تؤدي لفشل المشروعات الصغيرة وهي مشاكل مادية وتسويقية وتتظيمية

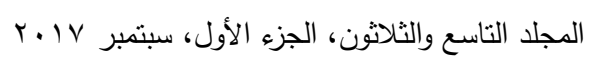


ومشاكل اقتصادية واوصت الدراسة العمل على نتجيع المراة في تأسس المشاريع الانتاجية الصغيرة والمتوسطة وكيفية ادارتها.

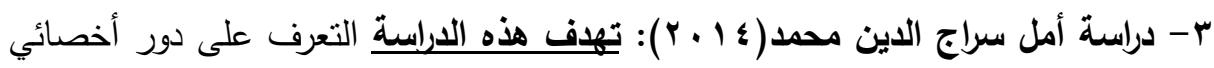
الجماعة في تتمية وعى الثباب بالعمل الحر، وأثنارت نتائج الدراسة إلى أن أهم الأدوار المدنية التي يقوم بها أخصائي الجماعة هي مساعدة الثباب في التعرف على المؤسسات التي تعمل في مجال العمل الحر والقيام بالتتسيق بين مراكز الثباب والمؤسسات التي تهنت

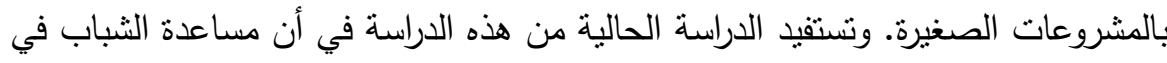

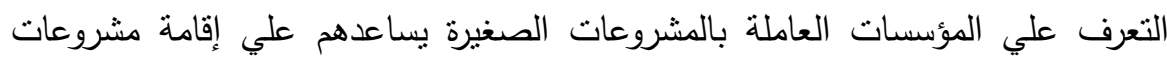
صغيرة ناجحة. ع - دراسة ريم محمد حسن سلامة(ه 1 • ؟): هدفت الدراسة الى القاء الضوء والتعرف على الملامح العامة والانشطة الرئيسية للمشروعات الصغيرة الممولة من الصندوق الاجتماعي للتتمية بمحافظة الثرقية والتعرف على دور الصندوق كأحد أهم المؤسسات التمويلية للمشروعات الزراعية الصغيرة وتقييم آثار قروض الصندوق الاجتماعي للتتمية لمشروعات تربية الماشية وتسمين العجول بمحافظة الثرقية كأهم الانشطة الممولة في مجال

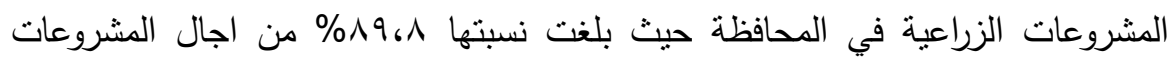

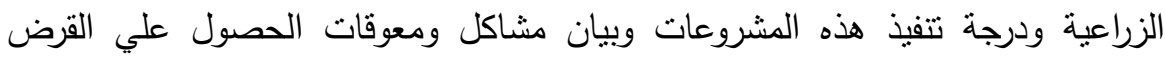
وتتفيذ المشروع وذلك من خلال الاعتماد على عينة ميدانية من محافظة الثرقية الى جانب البيانات الثانوية المنشورة وقد نم استخدام مقاييس الاحصاء الوصفي. وكانت أهم الهم النتائج التى توصلت اليها الدراسة أن ادارة الاقراض لا نركز على فئة الثباب وأن مساهمة

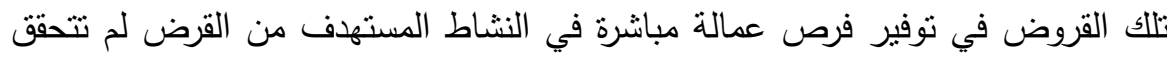
في حين شاهمت تللك القروض المخصص لنشاط تربية الماشية أو تسمين العجول لا يمكن أن يتتاسب مع توفير فرصة عمل كاملة ويمكن استخدامه كنشاط مكمل لعمل آخر أو حل

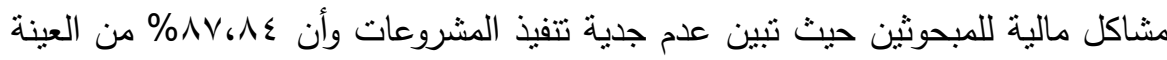

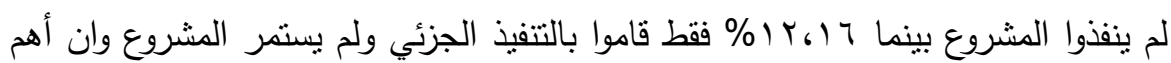


بدائل استخدام القرض هو زواج الابناء وتيسير السفر للخارج وشراء سيارة وبناء سكن خاص وبالرغم من توجيه القروض من قبل المقترضين لتحقيق أغراض أخري بعيدة عن التبن هدفي توفير فرص عمالة أو انتاج وتربية المانشية والتمسين فان اهتمام الجهات المقرضنة

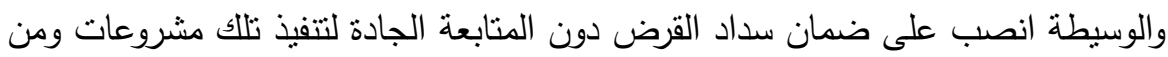
اهم المشاكل المرتبطة بالقرض هي ارتفاع أسعار الفائدة بينما ارتفاع أسعار مستلزمات الانتاج والرعاية البيطرية من أهم المشاكل المرتبطة بعدم تتفيذ المشروع وقد يرجع ذلكية ذلك لأن أكثر من • \& من المقترضين غير زراعين.

\section{الإسار اللنظليى للتراسما}

النظريات الاجتماعية المفسرة أولا: المدخل الإيكولوجي: نظرية الأنساق والإيكولوجيا البشرية، التي تُعْى بالتفاعلات المنبادلة

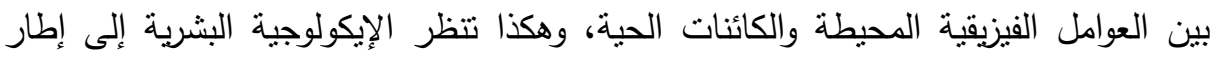

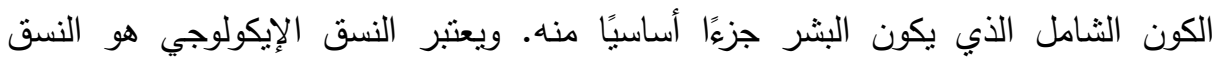
الوظيفي الناتج عن التفاعل بين الكائنات الحية والعوامل المحيطة وتنساعد نظرية الأنساق لئن الإيكولوجية على تتمية منظور جديد يوصف بأنه تطوري تكيفي يعتمد على التفاعلات

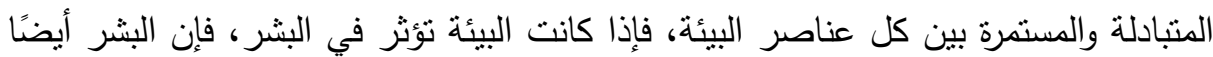

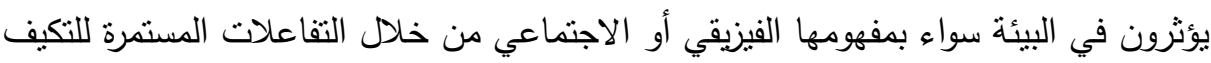

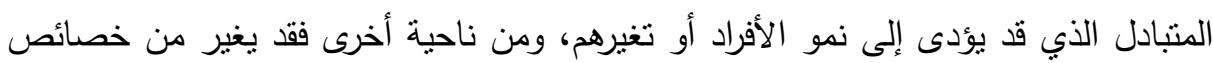
البيئة (السيد عبد العاطي السيد : و 1997).

وتهتم النظرية الإيكولوجية بكل من العوامل الداخلية والخارجية المؤثزة في النسق الإيكولوجي حيث أن العوامل الداخلية المؤثرة على المشروعات الصغيرة والخارجية. ومفهوم الإيكولوجية الاجتماعية لا يُعنى فقط بالآثار المباشرة للبيئة، ولكنه يُعْنى بتوزيع وتكوين الجماعات التي تعيش في هذه البيئة، والبيئة والسكان هما العنصران الرئيسان لتحليل

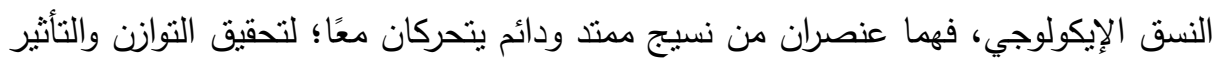

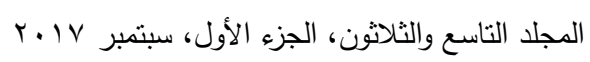


المنبادل، فالبيئة هي مشكلة التكيف أو موضوعه والسكان هم العنصر الحيوي، والنسق الإيكولوجي هو ميكانيزم التكيف، وبمعنى آخر فإن استجابة السكان للبيئة وتفاعلهم معها هو هونه

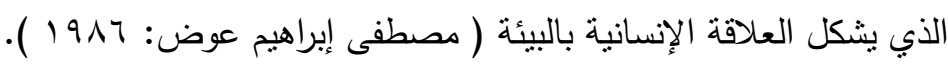

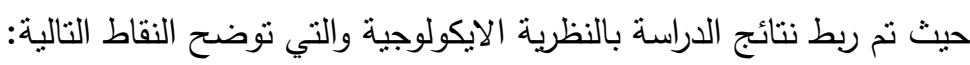
1-تهتم النظرية الإيكولوجية بكل من العوامل الداخلية والخارجية المؤثرة في النسق الإيكولوجي لإني حيث أن العوامل الاخلية المؤثزة على المشروعات الصغيرة الصنيرة والخارجية. r-هذا وتفبد نظرية البيئة الدراسة الحالية في الجوانب الآتية:

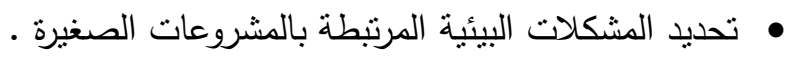

• التعرف على الاثار الاجتماعية للايون المتعثرة من خلال دراسة شاملة لبيئة الانسان.

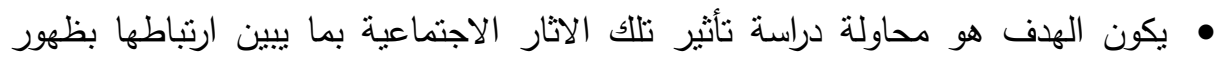
المشكلات البيئية والاجتماعية المرتبطة بالمشروعات الصغيرة مع إمكانية تحسين تللك

$$
\text { الظروف لتفادي عودة ظهور المشكلات مرة أخري . }
$$

تفيد في وضع الحلول والمقترحات التي تساعد في مواجهة المشكلات الاجتماعية المرتبطة بالمشروعات الصغيرة ومتتاهية الصغر ( الفقر - البطالة) من خلال منظومة بيئية شاملة لكل الأبعاد والمتغيرات التي يمر بها الانسان في حياته . باتهن

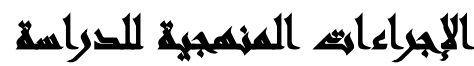

ا - نوع الدراسة: تعتبر الدراسة من الدراسات الوصفية لانها انسب انواع الدراسات

$$
\text { الملائمة لطبيعة نوع الدراسة . }
$$

ץ-منهج الدراسة: المستخدم هو المنهج الانثربولوجي من خلال دراسة حالات المتعثرين بعدم سداد القروض لبعض الثباب من محافظتي القاهرة والفيوم ـ لقد تم استخدام اكثر من أداة لجمع البيانات من الميدان بهدف زيادة التعمق في فهم المشكلات القائمة وعدم الاكتفاء بالمظهر الخارجي لها، فرواج الباحث بين الوسائل الكيفية عند جمع البيانات محاولا

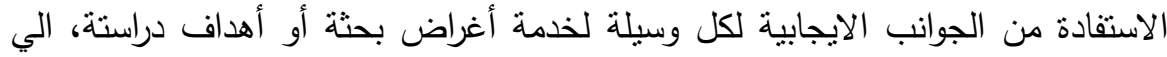


الجوانب غير الظاهرة في نفوس افراد المجتمع كما تمكن المقابلة كاسلوب منهجي في جمع

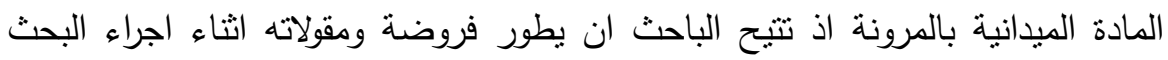

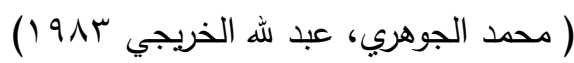
ولقد اعتمدت المقابلة في فهم ظروف الاقتراض للمبحوثين وطبيعة المشروعات التي لهيجي تمت وعوامل تعثز هذه المشروعات وفي رصد الاثار الاجتماعية والاقتصادية التي ترتبيت

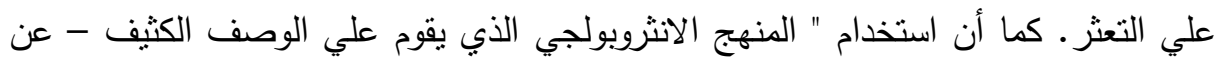

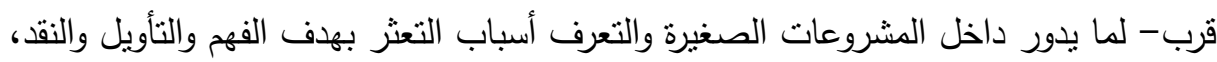

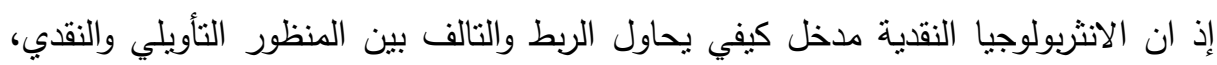

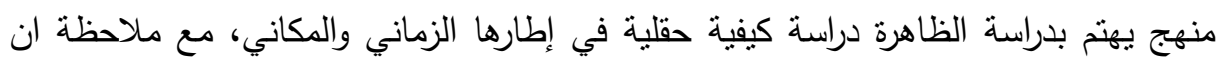
المنهج لا يسعي إلي رصد السلوك الظاهر ذاته، بل انه يسعي إلي تفسير ما يكمن وراء هذا

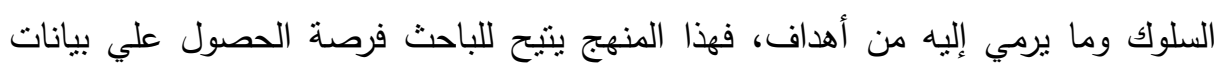
انتوجرافية ( وصفية كيفية ) تمكن من رؤية الواقع. r- ادوات الاراسة استخدم الباحثون استمارة دليل المقابلة لجمع البيانات المتعلقة بالآثار

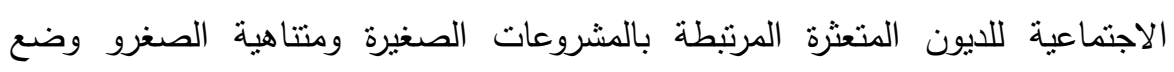

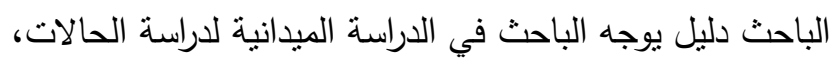

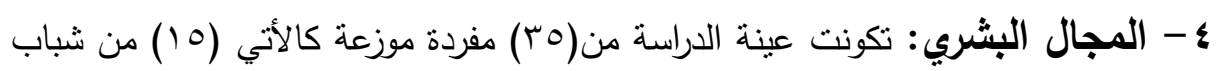

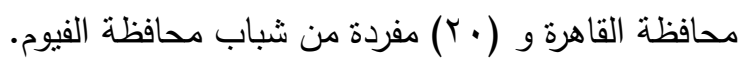
•-المجال المكاني: محافظتي القاهرة والفيوم

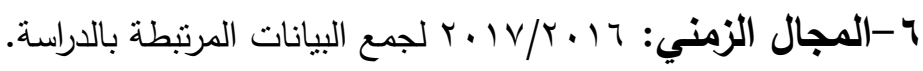
- V الجنسين) وقد راعت الدراسة الشروط النالية:

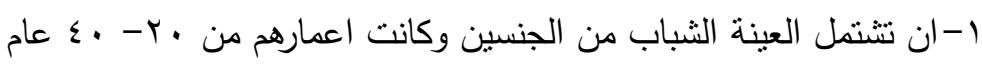
r-ان نتشنمل العينة المتعثرين في السداد 
جدول رقم(1): نوزيع عينة الدراسة وفقا للنوع

\begin{tabular}{|c|c|c|}
\hline$\%$ & العدد & النوع \\
\hline \%रा & ro & ذكور \\
\hline$\%$ \% q & 1. & اناث \\
\hline$\% 1 \ldots$ & $r_{0}$ & المجموع \\
\hline
\end{tabular}

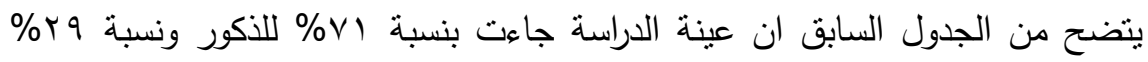

للاناث، ويتضح من هذا ان نسبة الاقبال علي المشروعات من الذكور اكثر من الاناث .

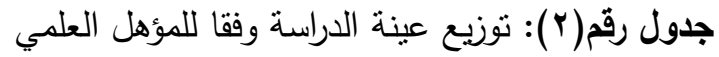

\begin{tabular}{|c|c|c|}
\hline$\%$ & العدد & المؤهل العلمي \\
\hline \%rV & $1 \pi$ & امى لايقرأولا يكتب \\
\hline$\% 7$ & $r$ & امي يقراً ويكتب \\
\hline$\% \leqslant \wedge$ & IV & متوسط \\
\hline$\% r$ & 1 & فوق المتوسط \\
\hline$\% 7$ & $\bar{r}$ & عالي \\
\hline$\% 1 \ldots$ & ro & المجموع \\
\hline
\end{tabular}

من الجدول السابق تثير البيانات الي ان عينة الدراسة جاءت للمؤهل العلمي بنسبة

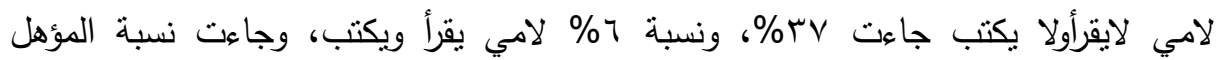

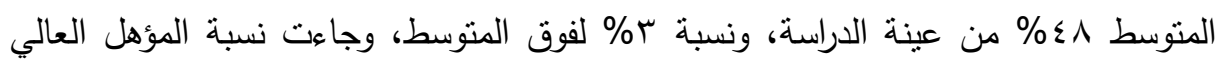
$\%$ \%

جدول رقم(ب): توزيع عينة الدراسة وفقا قيمة القرض

\begin{tabular}{|c|c|c|}
\hline$\%$ & العدد & قيمة القرض \\
\hline$\% \wedge \uparrow$ & $r$. & سيولة \\
\hline$\% \backslash \varepsilon$ & 0 & الالات \\
\hline$\% 1 \ldots$ & ro & المجموع \\
\hline
\end{tabular}

تشير البيانات الي ان عينة الدراسة جاءت قيمة القرض بنسبة ؟1 \% للسيولة، وفي حين جاءت بنسبة ؛ (\% للالات. 
فوزي عبد الرحمن إسماعيل وآخرون

جدول رقم(ع ): توزيع عينة الدراسة وفقا لخبرة المقترض السابقة

\begin{tabular}{|c|c|c|}
\hline$\%$ & العدد & خبرة المقترض \\
\hline \%ч. & $\overline{1 \xi}$ & توجد لديه خبرة \\
\hline$\%$ \%. & Y) & لاتوجد لدبه خبرة \\
\hline$\% 1 \ldots$ & ro & ألمجموع \\
\hline
\end{tabular}

يتضح من الجدول السابق ان عينة الدراسة جاءت بخبرة المقترض السابقة بنسبة . \%

لمن بملك الخبرة، ونسبة • ؛ \% لمن لايملك خبرة

جدول رقم(ه): توزيع عينة الدراسة وفقا لعدد العمال بالمشروع

\begin{tabular}{|c|c|c|}
\hline$\%$ & العدد & عدد العمال \\
\hline \%ाV & 7 & يوجد \\
\hline$\% \wedge r$ & rq & لايوجد \\
\hline$\% 1 \ldots$ & ro & المجموع \\
\hline
\end{tabular}

يتضح من الجدول السابق ان عينة الدراسة جاءت لعدد العمال بالمشروع بنسبة س^\%

لايوجد عمال بالمشروع، وجاءت نسبة VI V وجود عمال بالمشروع

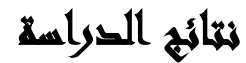

التساؤل الاول: أسباب نشأت الديون المتعثرة جدول(†): منتسط أعمار حالات المقترضين بالمشروعات الصغيرة والمتتاهية الصغر الصغر بمحافظة القاهرة

\begin{tabular}{|c|c|c|c|c|c|c|}
\hline \multicolumn{3}{|c|}{ المشروعات متناهية الصغر } & \multicolumn{3}{|c|}{ المشروعات الصغيرة } & \multirow{2}{*}{ الحالثة } \\
\hline طبيعة المشروع & موقع المشروع & السن & طبيعة المشروع & موقع المشروع & السن & \\
\hline تربية الطيور & باب الثعرية & ro & سائق تاكسي & الحي السابع مدينة & זT & 1 \\
\hline تربية الطيور & باب الشعرية & ro & محل جزارة & مدابغ الجلود & $r$. & $r$ \\
\hline عربة فول & باب الخلق & $r$ r. & محل بيع ملابس جاهزة & المنيل & rq & $r$ \\
\hline خياطة ملابس حريمي & باب الخلق & TV & محل بيع ملابس & شبرا مصر & ro & $\varepsilon$ \\
\hline تجارة الملابس الجاهزة & الحلمية & r. & ورشة ميكانيكا & روض الفرج & r & 。 \\
\hline خياطة ملابس حريمي & المطرية & rA & محل مستلزمات خياطة & شبرا مصر & $r \Lambda$ & 1 \\
\hline تجارة الخضروات & المطرية & $r v$ & محل اتيلية & مصر القديمة & $r$ r. & $v$ \\
\hline ورشة تصليح دراجات & عين شمس & r. & - & - & - & $\wedge$ \\
\hline- & - & $r \cdot, r$ & - & - & $r r, T$ & منوسط \\
\hline
\end{tabular}

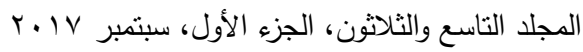


يثشير نتائج جدول (T) الي متوسط اعمار حالات الدراسة للمشروعات الصغيرة ومتتاهية الصغر في محافظة القاهرة تبين ان منوسط المقترض يبلغ ج, جr سنة بالنسبة للمشروعات

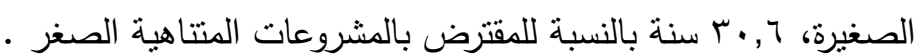

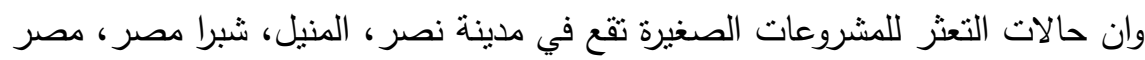

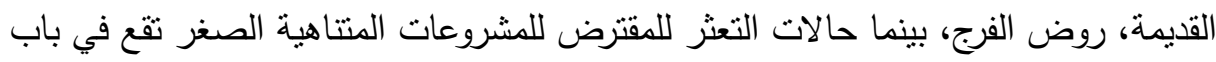

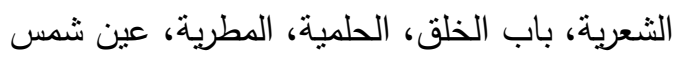
أما طبيعة المشروعات الصغيرة كانت من سيارات اجرة، محلات بيع ملابس، مستلزمات بـات خياطة، انيليه، ورش ميكانيكا، محل جزاره، بينما المشروعات متتاهية الصغر كانت من نربية الطيور، عربة فول، خياطة ملابس حريمي،تجارة الملابس الجاهزة، خياطة ملابس، تجارة الخضروات،ورشة تصليح دراجات بخارية جدول(V): منوسط أعمار حالات المقترضين بالة بالمشروعات الصغيرة والمتتاهية الصغر بمحافظة الفيور

\begin{tabular}{|c|c|c|c|c|c|c|}
\hline \multicolumn{3}{|c|}{ المشروعات متناهية الصغر } & \multicolumn{3}{|c|}{ المشروعات الصغيرة } & \multirow{2}{*}{ الحالة } \\
\hline طبيعة المشروع & موقع المشروع & 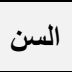 & المشروعة & موقع المشروع & 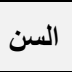 & \\
\hline تجارة الملابس الجاهزة بأنواعها & حدينة التعاونيات & $\varepsilon$. & سائق ناكسي & مدي البارودية & $r v$ & 1 \\
\hline تجارة الملابس الجاهزة بأنواعها & حي التعاونيات & rr & غيار سيارات & حي كيمان مدينة & $\leqslant 0$ & $r$ \\
\hline 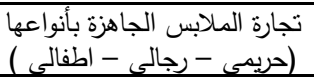 & حي دار الرماد & క0 & تجارة ادواتة & مركز سنورس & $\varepsilon r$ & r \\
\hline تربية الارانب & قرية المظاطلية & $\varepsilon$. & تجارة منتجات & بندر الفيوم & Tr & $\varepsilon$ \\
\hline 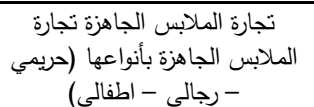 & قرية المظاطلية & $\leqslant 0$ & الجالجارة & بندر الفيوم & $\Gamma \varepsilon$ & 0 \\
\hline توك توك & قرية المظاطلية & $\leqslant \varepsilon$ & تجارة الاجهزة & حي الكمان الفيوم & $\leqslant 0$ & 7 \\
\hline تربية مواشي حديثة الولادة & قرية سيلا البلد & $\leq 0$ & تصنيع اكياس & النوبيري الفيوم & $\leqslant 0$ & V \\
\hline تربية مواثيى حديثة الولادة & قرية سيلا البلد & ro & تجارة الاعلاف & عزبة الالفي سنورس & TV & $\Lambda$ \\
\hline ورشة تصليح دراجات & قرية سيلا البلد & \{0 & سوبر ماركت & قرية الشواشنة & $\leqslant 0$ & 9 \\
\hline سايير انترنت & قرية سيلا البلد & ro & تصنيع احذية & مساكن المرور & «0 & 1. \\
\hline- & - & $\varepsilon \cdot, 7$ & - & - & $\varepsilon \cdot, r$ & متوسط \\
\hline
\end{tabular}


يشير نتائج جدول (V) الي متوسط اعمار حالات الدراسة للمشروعات الصغيرة ومتتاهية الصغر في محافظة الفيوم تبين ان منوسط المقترض يبلغ ب, •؛ سنة بالنسبة للمشروعات

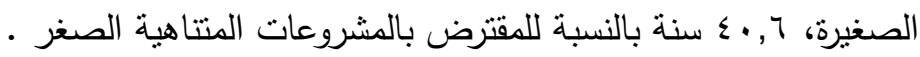

وان حالات التعثر للمشروعات الصغيرة ثقع في النوبيري، عزبة الالفي سنورس، قرية الثواثنة يوسف الصديق، مساكن المرور، حي البارودية،حي كيمان، مركز سنورس، بندر

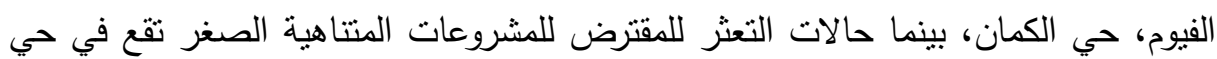
التعاونيات، حي دار الرماد مدينة، قرية المظاطلية، قرية سيلا البلد لهئل اما طبيعة المشروعات الصغيرة كانت من سيارات اجرة، تجارة قطع غيار سبارات، تجارة ادوات صحية، تجارة منتجات ورقية، تجارة الملابس الجاهزة، تجارة الاجهزة الكهربائية، تصنيع اكياس السكر ، تجارة الاعلاف، سوبر ماركت، تصنيع احذية

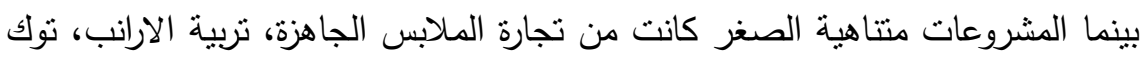
توك، تربية مواشي، ورشة تصليح دراجات، سايير انترنت.

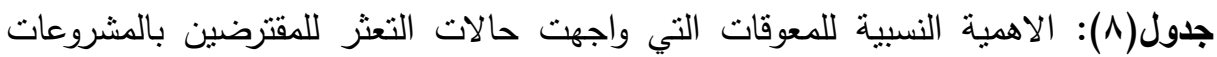
الصغيرة في محافظة الفيوم

\begin{tabular}{|c|c|c|c|c|}
\hline الاهدية النسبية & اللتكبيّة & التكرارات & 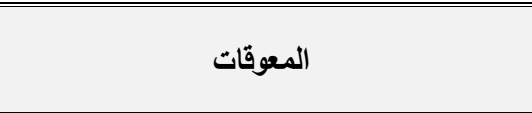 & م \\
\hline $1 \ldots$ & YI,Y^ & 1. & طول مدة الاجراءات وكثرة المستتدات & 1 \\
\hline A. & $I V, \cdot r$ & $\Lambda$ & كثرة عدد المنافسين للمشروع & r \\
\hline r. & $7, \Gamma \wedge$ & r & 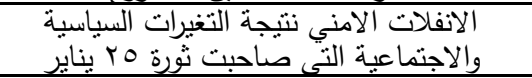 & r \\
\hline$r \cdot$ & $\varepsilon, Y T$ & r & قلة الخبرة للعاملين المتواجدين بالمشروع & $\varepsilon$ \\
\hline$\varepsilon$. & $\Lambda, 01$ & $\varepsilon$ & عدم توافر عمالة معاونة & 0 \\
\hline$\Lambda$. & $I V, \cdot r$ & $\Lambda$ & عدم توافز دراسة الجدوي الخاصة بالمشروعات & 7 \\
\hline $\mathrm{V} \cdot$ & $1 \leqslant, \wedge q$ & $\mathrm{~V}$ & عدم اختيار المكان المناسب لنجاح المشروع & $\mathrm{V}$ \\
\hline r. & $\varepsilon, Y_{\top}$ & r & تعرض المقترض لظروف المشروع طبيعية مما ادت & $\Lambda$ \\
\hline$r \cdot$ & $\varepsilon, Y \uparrow$ & $r$ & البيع بالآجل أدي إلى نقص السيولة & 9 \\
\hline 1. & $T, 1 T$ & 1 & إقتراض الحالة من أَصدقائه قبل الاقتراض & 1. \\
\hline & $1 \cdots, \cdots$ & $\sum V$ & 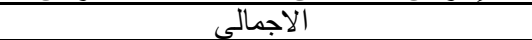 & $\pi$ \\
\hline
\end{tabular}


امكن للباحث من تحديد المعوقات التي اعترضت حالات التعثر للمقترضين بالمشروعات الصغيرة من الصندوق الاجتماعي بمحافظة الفيوم وهي طول مدة الاجراءات وكثرة المستتدات

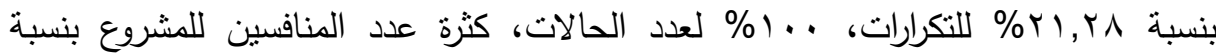

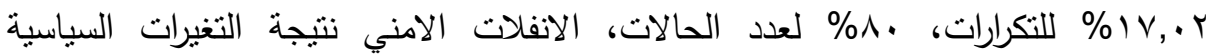

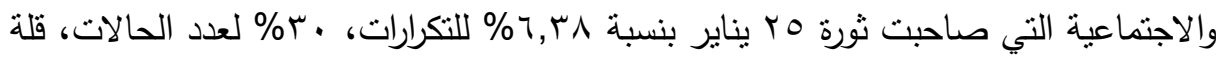

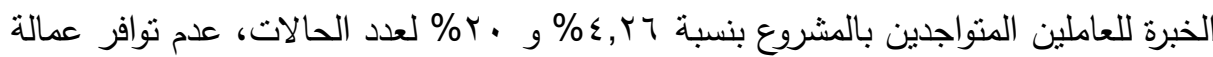

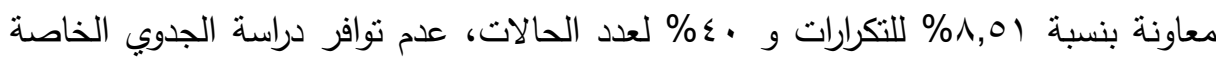

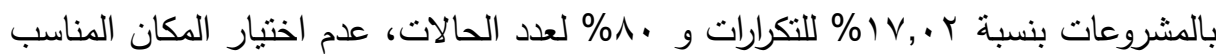

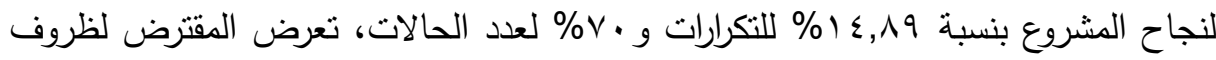

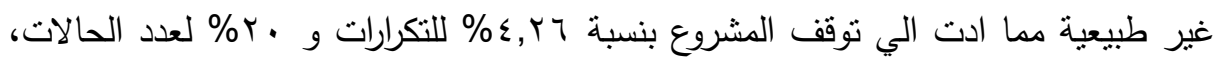

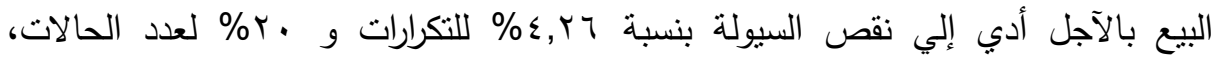

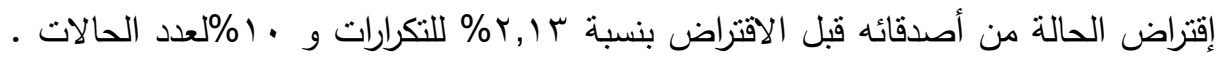
وبترتيب المعوقات التي اعترضت حالات التعثر للمقترضين بالمشروعات الصغيرة من الصندوق الاجتماعي بمحافظة الفيوم تبين ان (طول مدة الاجراءات وكثرة المستتدات) تحتل

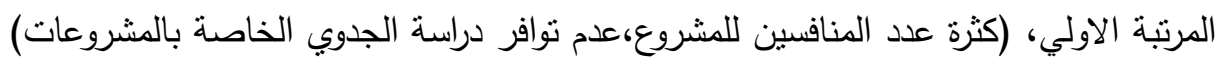
تحتل المرتبة الثانية، (عدم اختيار المكان المناسب لنجاح المشروع) تحنل المرنبة الثالثة، (عدم توافر عمالة معاونة) تحتل المرتبة الرابعة، (الانفلات الامني نتيجة التغيرات السياسية

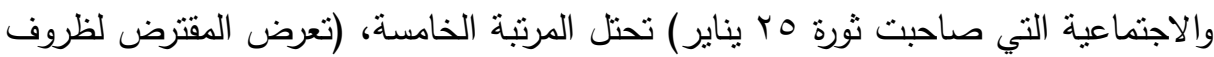

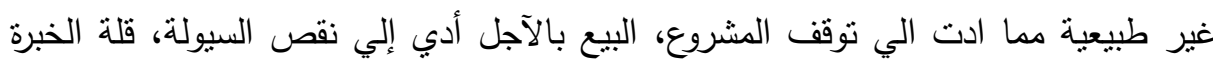

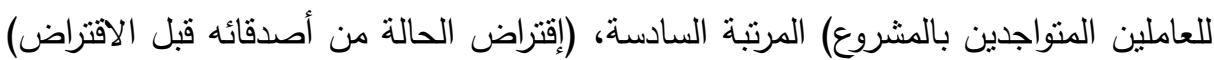

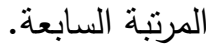


جدول(9): الاهمية النسبية لاسباب التعثر التي واجهت حالات التعثر للمقترضين

\begin{tabular}{|c|c|c|c|c|}
\hline \multicolumn{5}{|c|}{ بالمشروعات الصغيرة في محافظة الفيوم } \\
\hline الاهدية النسبية & الاهمية النسبية & التكرارات & أسباب التعثر & s \\
\hline $1 \ldots$ & ri, ro & 1. & الى التعثر في الاجراءات الحصول نتجة التقي تعويض مما ادي & 1 \\
\hline r. & 7, ro & r & والة حثرة اجراءات اللازمة للحصول علي التعرض في & r \\
\hline r. & 9, rVo & r & 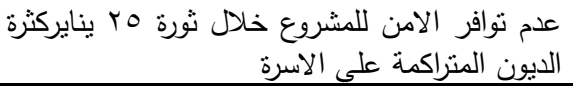 & r \\
\hline$\varepsilon$. & $1 Y, 0$ & $\varepsilon$ & عدم الإستعانة بأيدي عاملة لكبر المشروع & $\varepsilon$ \\
\hline r. & 7, ro & r & 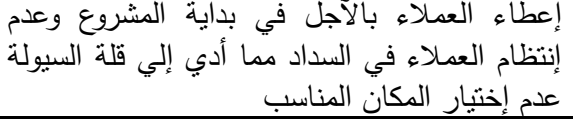 & o \\
\hline A. & ro & $\Lambda$ & المنافسةعدم عمل دراسة جدوي مناسبة & 1 \\
\hline r. & 7, ro & r & إرتفاع الأسعار و إنخفاض المبيعات & $\mathrm{v}$ \\
\hline 1. & r,IYo & 1 & إرتفاع التأمينات على العمال & $\Lambda$ \\
\hline & $1 \ldots$ & rr & 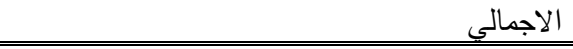 & 9 \\
\hline
\end{tabular}

أمكن للباحث من تحديد اسباب التعثر التي اعترضت حالات التعثر للمقترضين

بالمشروعات الصغيرة من الصندوق الاجتماعي بمحافظة الفيوم وهي طول الاجراءتئن

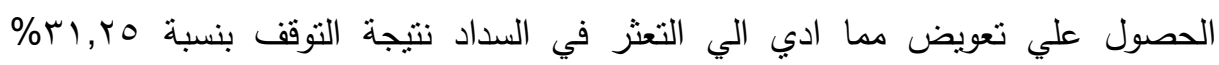

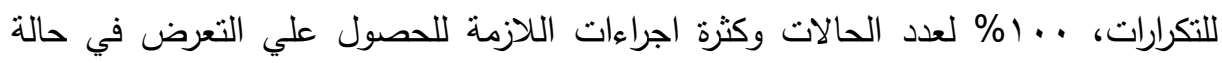

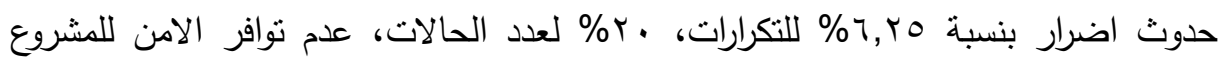

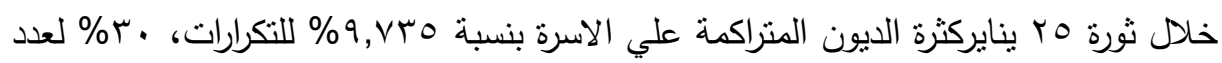

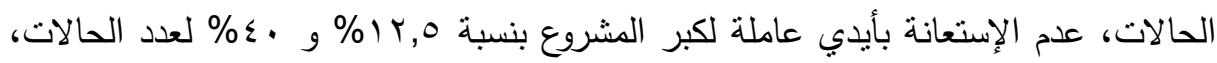

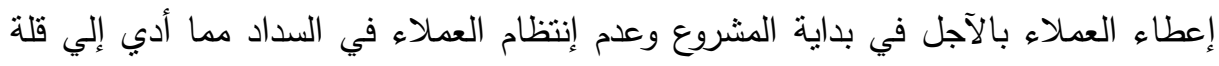

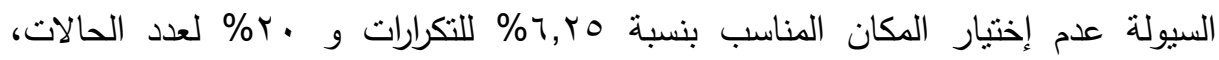

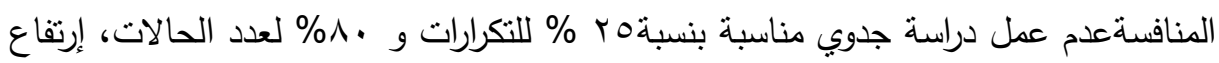

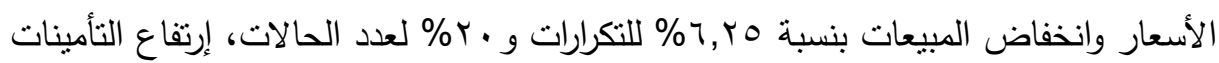

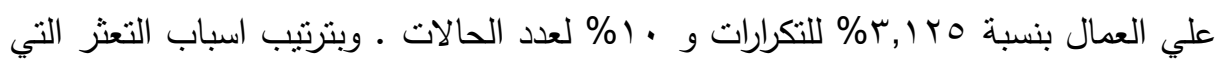


اعترضت حالات التعثر للمقترضين بالمشروعات الصغيرة من الصندوق الاجتماعي بمحافظة الفيوم تبين ان طول الاجراءات الحصول علي تعويض مما ادي الي التعثر في السداد نتيجة

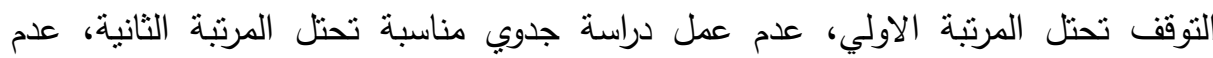

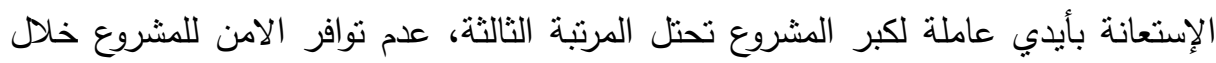

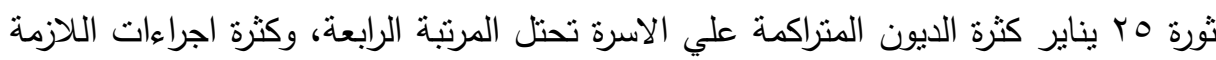

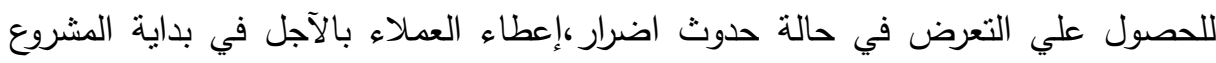

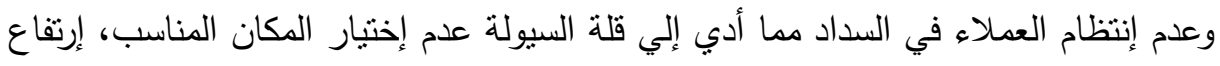
الأسعار وانخفاض المبيعات تحتل المرنبة الخامسة، إرتفاع التأمينات علي العمال تحنل إنل

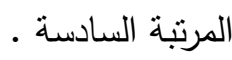
جدول(• (1): الاهمية النسبية للمعوقات التي واجهت حالات التعثر للمقترضين بالمشروعات متتاهية الصغر في محافظة القاهرة

\begin{tabular}{|c|c|c|c|c|}
\hline النسبية للعدد & اللتكراربية & التكرارات & المعوقات & م \\
\hline$T Y, O$ & $r \cdot, \lambda r$ & o & 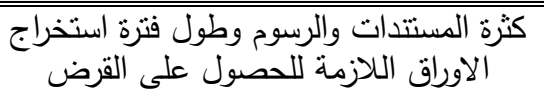 & 1 \\
\hline$r v, 0$. & $1, r, 0$. & $\bar{r}$ & ارتفاع أسعار السلع & r \\
\hline$r v, 0$. & $1,0$. & $r$ & المنافسة الثديدة لمشروعات المقترضين & $r$ \\
\hline$T r, 0$. & $r \cdot, \Lambda r$ & 0 & عدم وجود دراسات جدوي كافية للمشروعات & $\varepsilon$ \\
\hline$r v, 0$. & $1,0.0$. & r & عدم توافر السيولة الكافية & 0 \\
\hline$r v, 0$. & $1, r, 0$. & r & الانفلات الأمنى خلال ثورة مب يناير & 1 \\
\hline IY,O. & $\varepsilon, 1 \mathrm{~V}$ & 1 & قلقة الخبرة للمقترضين & $\mathrm{v}$ \\
\hline $1 Y, 0$. & $\varepsilon, 1 \mathrm{~V}$ & 1 & عدم تقسيم العمل بينه وبين شُريكه & $\Lambda$ \\
\hline & $1 \ldots$ & $T \varepsilon$ & 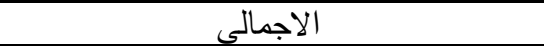 & 9 \\
\hline
\end{tabular}

امكن للباحث من تحديد المعوقات التي اعترضت حالات التعثر للمقترضين بالمشروعات متتاهية الصغر من الصندوق الاجتماعي بمحافظة القاهرة وهي كثرة المنتتدات والرسوم وطول

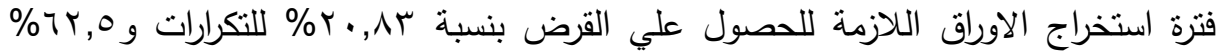

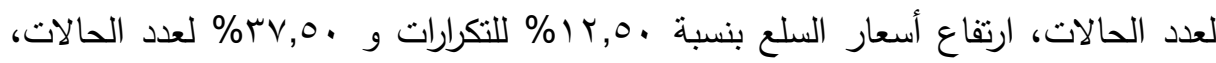

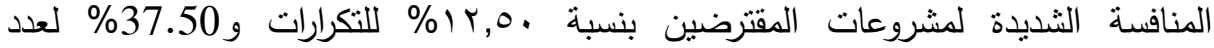

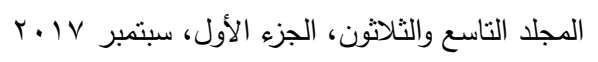




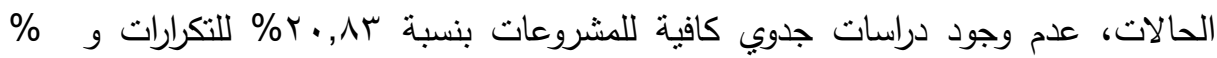

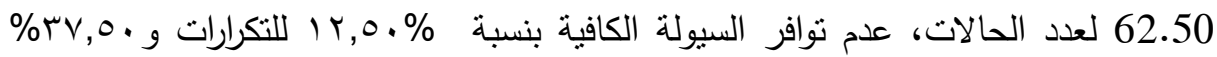

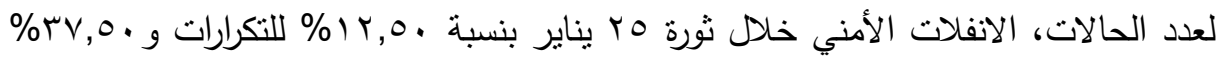

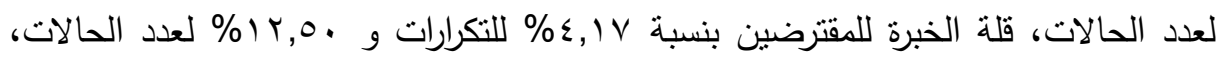

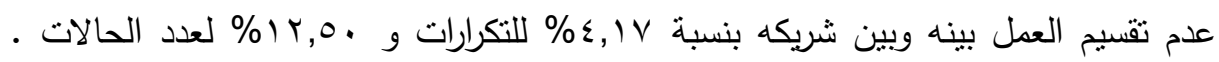
وبترتيب المعوقات التي اعترضت حالات التعثر للمقترضين بالمشروعات متتاهية الصغر من الصندوق الاجتماعي بمحافظة القاهرة تبين ان كثرة المستتدات والرسوم وطول فترة استخراج الاوراق اللازمة للحصول علي القرض، عدم وجود دراسات جدوي كافية للمشروعات تحتل

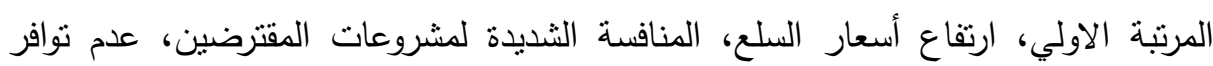
السيولة الكافية، الانفلات الأمني خلال ثورة هب بناعة يناير تحتل المرتبة الثانية، قلة الخبرة

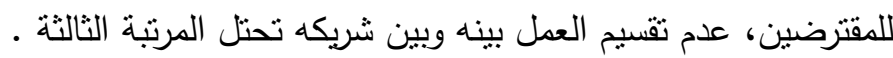
جدول(1): الاهمية النسبية لاسباب التعثر التي واجهت حالات التعثر للمقترضين بالمشروعات متتاهية الصغر في محافظة القاهرة

\begin{tabular}{|c|c|c|c|c|}
\hline الاهمبية & للالتهرية النسبة & التكرارات & 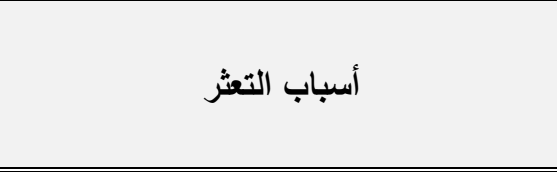 & r \\
\hline$\sum Y, \wedge T$ & $11,0 \leq$ & $r$ & ارتقاع أسعار للمشروعات المعثرة & 1 \\
\hline$\sum Y, \wedge \uparrow$ & $11,0 \leq$ & $r$ & قلة خبرة المقترضين للمشروعات & r \\
\hline$\sum Y, \wedge \uparrow$ & $11,0 \leqslant$ & r & وعدم اختيار المكان المناسب & r \\
\hline YA,OV & $\vee, 79$ & r & المنافسة الثديدة بين المشروعات & $\varepsilon$ \\
\hline$r \wedge, O V$ & $V, 79$ & r & عدم الدعاية الكافية للمشروع & 0 \\
\hline rA, OV & $\vee, 79$ & r & البيع عن طريق الاجل أثز على السيولة & 7 \\
\hline rA, OV & $\vee, 79$ & r & عدم وجود السيولة الكافية لشراء بضاعة اخري & $\mathrm{V}$ \\
\hline $1 \varepsilon, Y q$ & r,人o & 1 & 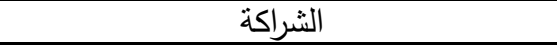 & $\Lambda$ \\
\hline$V 1, \leq r$ & $19, r \mu$ & 0 & عدم وضـع دراسة جدوي جيدة للمشروعات & 9 \\
\hline$\sum Y, \wedge \uparrow$ & $11,0 \leqslant$ & $r$ & حدوث الانفلات الأمنى & 1. \\
\hline- & $1 \cdots$ & $r 7$ & الاجمالّ & \\
\hline
\end{tabular}


أمكن للباحث من تحديد اسباب التعثر التي اعترضت حالات التعثر للمقترضين بالمشروعات متتاهية الصغر من الصندوق الاجتماعي بمحافظة القاهرة وهي ارتفاع أسعار

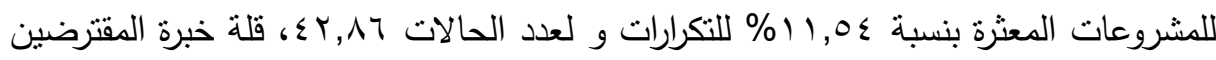

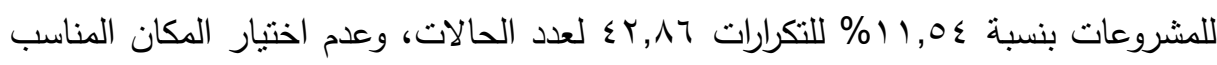

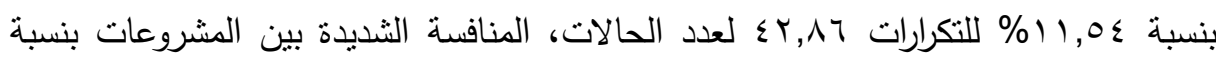

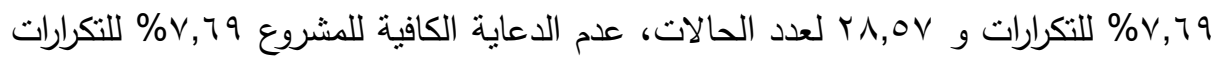

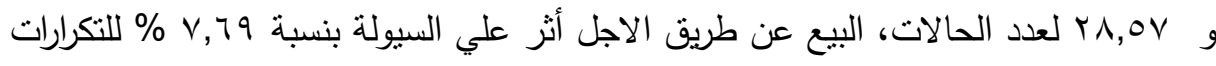

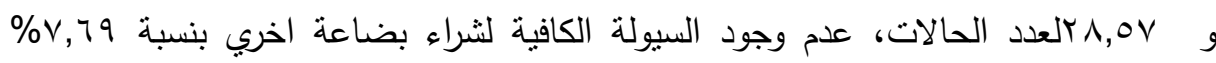

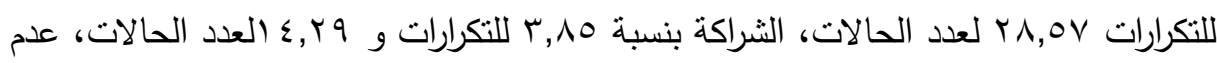

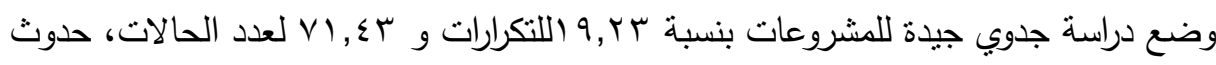

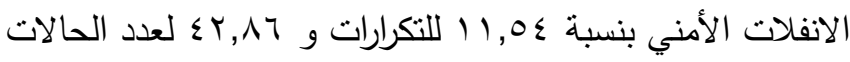
وبترتيب اسباب التعثر التي اعترضت حالات التعثر للمقترضين بالمشروعات متتاهية الصغر من الصندوق الاجتماعي بمحافظة القاهرة عدم وضع دراسة جدوي جيدة للمشروعات تحنل المرتبة الاولي. ارتفاع أسعار للششروعات المعثرة، قلة خبرة المقترضين للمشروعات، وعدم اختيار المكان المناسب، حدوث الانفلات الأمني تحنل المرنبة الثانية

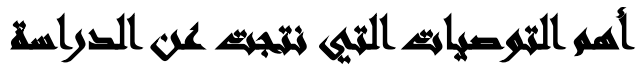

اـ العمل علي توافر الموارد اللازمة لإقامة المشروعات وتشهيل الإجراءات التظيمية وتخفيض الضرائب لكي يقبل الثباب للعمل بهذه المشروعات. r. العمل علي تدريب الثباب وإمدادهم بالمعارف والمعلومات واستثمار قدراتهم في تتفيذ هذه المشروعات يساعد في تحسين مستوى معيشتهم. 
r. وضع مقترحات وخطط وبرامج لتتفيذ المشروعات وتشغيلها ومتابعتها وتقييمها وتقويمها وتحديد الاولويات على المستوي القريب والبعيد والوصول لتوصيات جادة وقابلة للتنفيذ لعرضها على صناع متخذي القرار

ع. النظر في أسعار الفائدة العالية الممنوحة لعملاء التمويل الأصغر حتى لا تصبح هذه القروض سبباً في زيادة الإفقار بدلاً من كونها مساعده للخروج من دائرة الفقر .

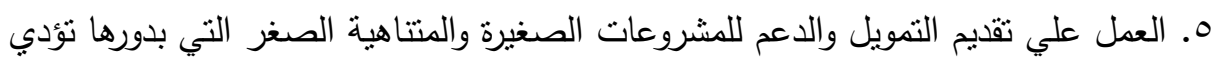
إلي استمرار هذه الشروعات وبالتالي توفر فرص عمل أكبر للشباب.

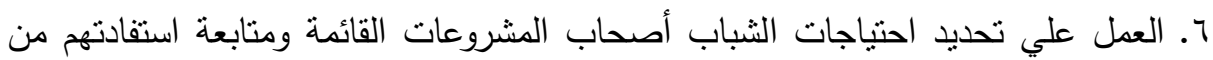
خدمات الجمعية يؤدي إلي استمرار هذه المشروعات.

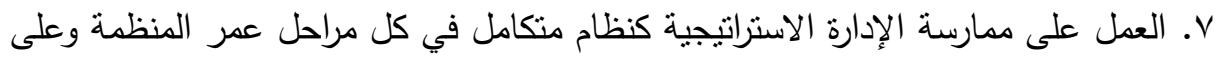
مختلف المستويات، ^. ضرورة تدعيم الاتجاهات الإيجابية لدي الثباب وتزويدهم بالمعلومات وإكسابهم المهارات الفنية المتعلقة بإدارة المشروعات، لكي يساهم في الإقبال نحو العمل بالصناعات الصغيرة وأيضاً ضرورة علاج الاتجاهات السلبية.

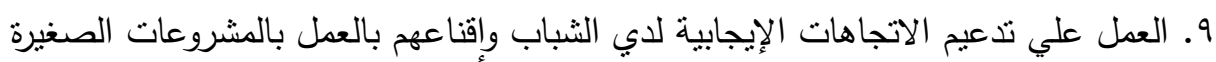
يؤدي إلي توفير فرص عمل له وبالتالي تحسين دخولهم.

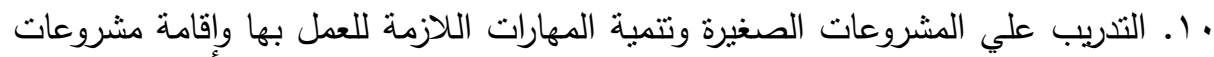
جديدة ناجحة مما بساعد علي زيادة الدخل للشباب.

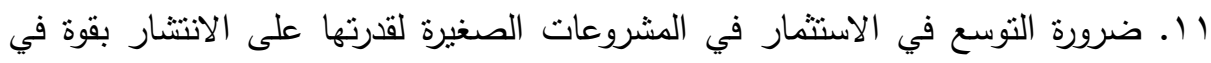
المجتمعات المحلية مما ينتج عنه نشر الرفاهية وتحسين مستوي المعيشة والتوزيع العادل لتمار التتمية بل وتحقيق التتمية المنشودة في كل محافظات مصر بدرجة عالية من 


\section{المرالئ}

أماني سليمان محمد(ب ( †): إسهامات المشروعات الصغيرة في تتمية القرى الأكثر فقراً،

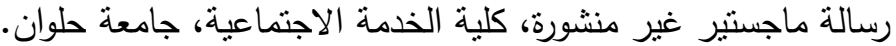

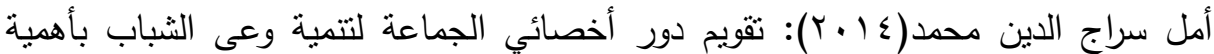
العمل الحر، رسالة ماجستير غير منشورة، كلية الخدمة الاجتماعبة، جامعة التية الفية حلوان.

إيهاب طلعت الثايب(· • • ץ): آثر تمويل المشروعات متتاهية الصغر على مستوى معيشة

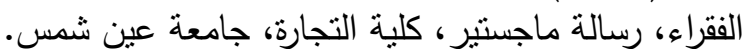

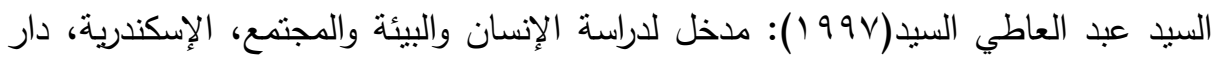

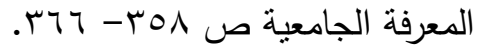

حسان خضر (سبتمبر ץ +. ץ): تتمية المشروعات الصغيرة، دورية جسر التتمية، العدد التاسع،

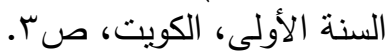

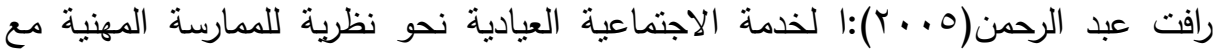

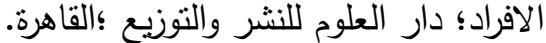

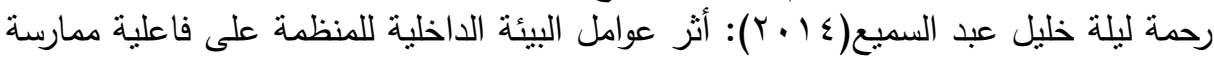

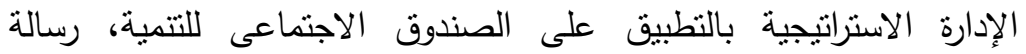
ماجستير كلية التجارة قسم إدارة اعمال جامعة بنها.

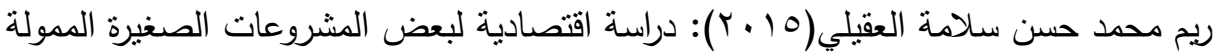

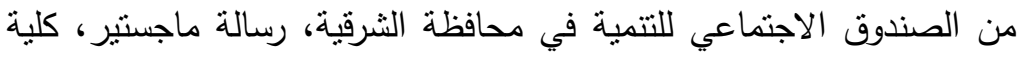
الزراعة جامعة الزقازيق.

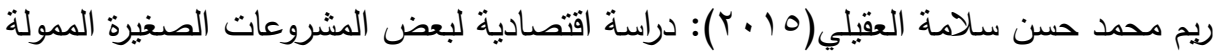

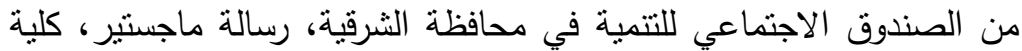
الزراعة جامعة الزقازيق.

ريهام محمد محمدين خير الدين(ب ( ب): المشروعات الصغيرة وعلاقتها بتغير نمط الحياة لدي المرأة " دراسة ميدانية محافظة دمياط" رسالة ماجستير ، معهز الدراسات

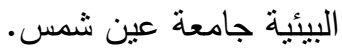

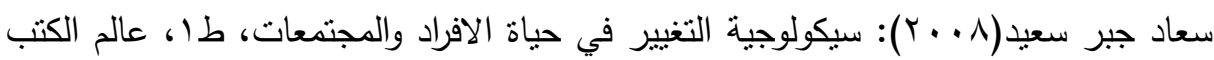

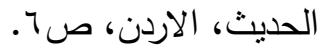




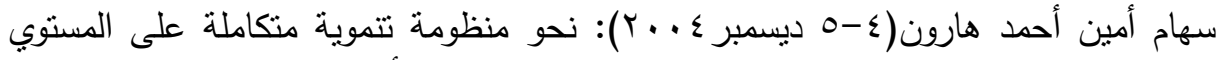

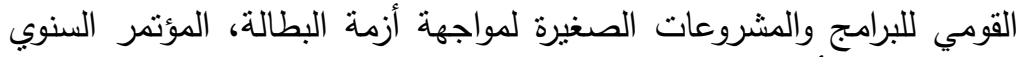

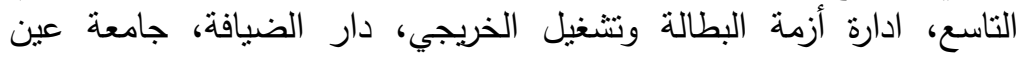

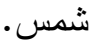

صابر أحمد عبد الباقي(0 × . ب): المشروعات الصغيرة وأثزها في القضاء على البطالة، كلية

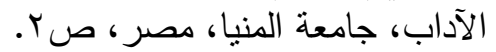

محسن أحمد الخضيري(197 (1) الآد): الديون المتعثرة الظاهرة..الأسباب..العلاج (القاهرة: إيتراك،

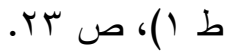

مصطفى إيراهيم عوض(1) (1) (1): التتمية الاقتصادية وتغير البناء الاجتماعي التقليدي في مجتمع واحة الفرافرة ( رسالة دكتوراه غير منشورة)، معهد البحوث الإداء والدراسات

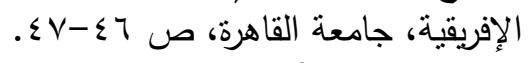

نرمين إبراهيم حلمي(1 (1) ج): آليات التمكين المستدام بالجمعيات الأهلية العاملة في مجال

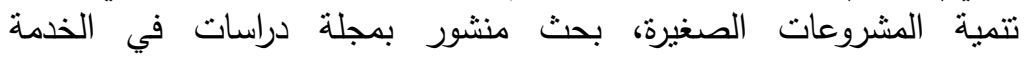
الاجتماعية والعلوم الإنسانية، كلية الخدمة الاجتماعية، جامعة حلوات التوان.

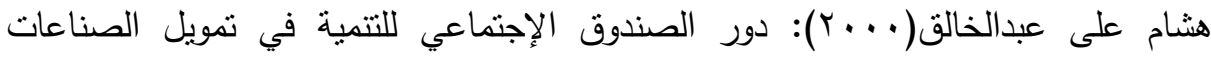
الصغيرة في مصر ، رسالة ماجستير ، كلية التجارة جامعة عين شمس.

Randa Helmi Abbas,(2002): Small Scale Enterprise in Egypt, Cairo American University.

Wall , Bruce, " Busincess indicators", Business Datc Mar Vol ,10lssue 1,2002,pp.1-3. 
مجلة العلوم البيئية

معهد الدراسات والبحوث البيئة - جامعة عين شمس البية

\title{
SOCIAL IMPACTS OF TROUBLED DEBTS RELATED TO MICRO AND MICRO ENTERPRISES
}

[5]

Esmail, F. A. ${ }^{(1)}$; Elshafee, M. S. ${ }^{(2)}$ and Salm, A. M. E. 1) Faculty of Girls, Ain Shams University 2) Non-perforing Debt Department, The Board of Directors of the Social Fund for Development

\begin{abstract}
One of the features of small projects is the provision of employment opportunities for young people. This contributes to the advancement of social life. Every member of the humanitarian community, when working, feels that he is an active member of society and that he is a contributor to social development. Social security as a guarantee of a happy social life. Given the economic importance of small enterprises as the mechanism of the era in reducing unemployment and the various social, psychological and economic consequences resulting from it, this mechanism was introduced because of its advantages in the field of production and services necessitated by the need to exist alongside large enterprises. It is therefore necessary to work to increase the efficiency of these projects in Egypt and overcome all the difficulties they face to increase their role in the operation in particular and in the process of economic development in general.The study used the anthropological method through the use of a sample of the study population for some young men and women from Cairo and Fayoum governorate. The study tools used are questionnaire questionnaire and interview to collect data on the social effects of the bad debts associated with small and micro projects. (15) of the youth of Cairo governorate and (20) one of the youth of Fayoum governorate. The study has reached several conclusions, including the need to emphasize the pivotal role played by the small enterprise in most developed and developing countries, both as an effective tool to reduce
\end{abstract}

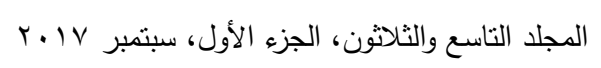


فوزي عبد الرحمن إسماعيل وآخرون

unemployment and employment of youth and young and new graduates. The study recommends the importance of increasing coordination between the central ministries and local administrations to address bureaucratic obstacles Facing small and medium-sized enterprises. The economic climate must be stabilized by taking into account the position of small and medium enterprises when issuing serious laws and regulations affecting projects, Loans and lower interest rates. 